\title{
Valorization of waste forest biomass toward the production of cello-oligosaccharides with potential prebiotic activity by utilizing customized enzyme cocktails
}

\author{
Anthi Karnaouri, Leonidas Matsakas, Eleni Krikigianni, Ulrika Rova and Paul Christakopoulos*
}

\begin{abstract}
Background: Production of value-added materials from lignocellulosic biomass residues is an emerging sector that has attracted much attention as it offers numerous benefits from an environmental and economical point of view. Non-digestible oligosaccharides represent a group of carbohydrates that are resistant to gastrointestinal digestion, and therefore, they are considered as potential prebiotic candidates. Such oligosaccharides can derive from the biomass cellulose fraction through a controlled enzymatic hydrolysis that eliminates the yield of monomers.

Results: In the present study, hydrolysis of organosolv-pretreated forest residues (birch and spruce) was tested in the presence of four cellulases ( $\mathrm{EG} 5, \mathrm{CBH} 7, \mathrm{CBH} 6, \mathrm{EG} 7)$ and one accessory enzyme (LPMO). The optimal enzyme combinations were comprised of 20\% EG5, 43\% CBH7, 22\% TtLPMO, 10\% PaCbh6a and 5\% EG7 in the case of birch and 35\% EG5, 45\% CBH7, 10\% TtLPMO, 10\% PaCbh6a and 5\% EG7 in the case of spruce, leading to 22.3\% and $19.1 \mathrm{wt} \%$ cellulose conversion into cellobiose, respectively. Enzymatic hydrolysis was applied on scale-up reactions, and the produced oligosaccharides (consisted of $>90 \%$ cellobiose) were recovered and separated from glucose through nanofiltration at optimized temperature $\left(50^{\circ} \mathrm{C}\right)$ and pressure $(10 \mathrm{bar})$ conditions, yielding a final product with cellobiose-to-glucose ratio of 21.1 (birch) and 20.2 (spruce). Cellobiose-rich hydrolysates were tested as fermentative substrates for different lactic acid bacteria. It was shown that they can efficiently stimulate the growth of two Lactobacilli strains.
\end{abstract}

Conclusions: Controlled enzymatic hydrolysis with processive cellulases, combined with product recovery and purification, as well as enzyme recycling can potentially support the sustainable production of food-grade oligosaccharides from forest biomass.

Keywords: Non-digestible oligosaccharides, Cellobiose, Processive endoglucanases, Prebiotics, Enzyme hydrolysis, Nanofiltration

\section{Background}

Prebiotics were first defined as "non-digestible food ingredients that beneficially affect the host by selectively stimulating the growth and/or activity of one or a limited number of bacteria in the colon that can improve the host

\section{*Correspondence: paul.christakopoulos@ltu.se}

Biochemical Process Engineering, Chemical Engineering, Department of Civil, Environmental and Natural Resources Engineering, Luleå

University of Technology, Luleå, Sweden health" [1]. A potential prebiotic compound can be any food ingredient and it satisfies certain characteristics such as: (1) resistance to gastric acidity, hydrolysis by mammalian enzymes and gastrointestinal absorption, (2) fermentation by intestinal microbiota, (3) selective stimulation of the growth and/or activity of the intestinal bacteria that contribute to health and well-being. According to the first characteristic, resistance to digestion, the prebiotic does not need to be completely indigestible, but significant

(c) The Author(s) 2019. This article is licensed under a Creative Commons Attribution 4.0 International License, which permits use, sharing, adaptation, distribution and reproduction in any medium or format, as long as you give appropriate credit to the original author(s) and the source, provide a link to the Creative Commons licence, and indicate if changes were made. The images or other third party material in this article are included in the article's Creative Commons licence, unless indicated otherwise in a credit line to the material. If material is not included in the article's Creative Commons licence and your intended use is not permitted by statutory regulation or exceeds the permitted use, you will need to obtain permission directly from the copyright holder. To view a copy of this licence, visit http://creativeco mmons.org/licenses/by/4.0/. The Creative Commons Public Domain Dedication waiver (http://creativecommons.org/publicdomain/ zero/1.0/) applies to the data made available in this article, unless otherwise stated in a credit line to the data. 
amounts should be available in the intestine (especially the large bowel) in order to provide a fermentation substrate [2]. Various health benefits are associated with the NDOs intake, such as improved blood lipid metabolism, regulation of gastrointestinal function, prevention and treatment of constipation, increased vitamin synthesis and improved human immunity. Additionally, they can be used as protective agent when bacteria encounter changes of temperature, $\mathrm{pH}$ and other growth conditions [3]. Prebiotic intake is possible to be obtained through the diet through certain fruits and vegetables; however, the levels of the natural prebiotics are too low, indicating the need for enhancing the levels of prebiotic intake [4].

A wide variety of dietary carbohydrates are considered as potential substrates for bacterial fermentation, with resistant starch being the most quantitatively important. Additionally, non-starch oligosaccharides, including plant-derived substrates such as pectin, cellulose and hemicellulose, have a large contribution to the group of non-digestible oligosaccharides (NDOs). NDOs are defined as those carbohydrates with a low degree of polymerization (DP) (they contain between 3 and 10 sugar units) and therefore a low molecular weight [5]. Commercial NDOs are mixtures of oligosaccharides with variable DP [6]. The concept of the NDOs first originated from the observation that the anomeric $C$ atom in position 1 or 2 of the monosaccharide units of some dietary oligosaccharides has a configuration that makes their glycosidic bonds nondigestible to the hydrolytic activity of the human digestive enzymes [7]. The main categories of NDOs include carbohydrates in which the monosaccharide unit is fructose, galactose, mannose, arabinose, glucose and/or xylose, as well as galacturonic acid in the case of pectin [7].

Cello-oligosaccharides (COS) are linear oligosaccharides that are composed of $\beta$-1,4-linked glucopyranose units. COS comprise a group of novel important functional oligosaccharides with significant interest [8] and many potential applications in the feed and food industry as potential prebiotic compounds [9-11]. These oligosaccharides, as well as the disaccharide cellobiose, have been shown to enhance the growth of lactic acid bacteria, and their use as prebiotics has been suggested [12, 13]. Additionally, they can derive from the most abundant carbon source on Earth: lignocellulose; therefore, they are, potentially, the most abundant available NDOs. Production of foodgrade prebiotic COS from lignocellulosic biomass, more specifically from forest farming residues and forest industry by-products, constitutes a novel attractive process that enforces the sustainable use of biomass resources. These residues are currently being burned for energy recovery in power plants and households with a sale price of approx. $50-100 €$ per ton dry weight and could potentially be utilized for products of higher value. In Sweden, the forest industry has so far been the focus for the development of a bioeconomy. From both a forestry sector and a society point of view, there is a rapidly growing interest in new technologies that can convert renewable, low-cost biomass from the forest into high-value bulk products, e.g., transportation fuels, fine chemicals and materials.

Two main strategies can be used for the production of COS; acid-based and controlled enzyme-based hydrolysis of the cellulose. The latter is considered as more attractive due to the use of milder reaction conditions and lower production of monomers [5]. However, there is still limited information regarding the large-scale production of COS. The cellobiohydrolase belonging to the glycosyl hydrolase family 7 (CBH7) and the endoglucanase of the family 5 (EG5) are two enzymes of pivotal importance for the production of cellobiose from forest materials, such as spruce and birch [13]. Both belong to a group of enzymes called processive, whose main feature of action is that they release soluble products from the chain ends of a cellulose molecule, and moreover, they perform several hydrolysis cycles after the first cleavage by moving on the same cellulose chain $[14,15]$. In the present study, we evaluated different processive endoglucanases of bacterial and fungal origin, belonging to $\mathrm{GH} 9, \mathrm{GH} 6$ and $\mathrm{GH} 48$ families for their ability to release COS from model substrates and lignocellulosic biomass residues. The most promising candidates were selected and integrated in enzyme cocktails together with CBH7 and EG5, and their synergistic mode of action was examined. Lytic polysaccharide monooxygenase of auxiliary family 9 was also included in the mixture, as this enzyme has been identified as a main component of cellulolytic cocktails due to its ability to facilitate the activity of hydrolases by creating new chain ends, promoting the defibrillation of cellulose fibers and improving the overall degradation process $[16,17]$. The biomass-derived COS, consisted mostly of cellobiose, were tested for their ability to stimulate the growth of gut microbiota (Lactobacilli and Bifidobacteria species). To our knowledge, this is the first study that not only includes the sustainable production of food-grade COS from waste forest residues, but also the confirmation that they can support the growth of different probiotic strains.

\section{Results}

Screening of processive cellulases and mode of action i. Hydrolysis on cellulosic polysaccharides and lignocellulosic substrates

Different cellulases of bacterial and fungal origin were screened for their mode of action, and the product profile on both polysaccharidic substrates and oligosaccharides was determined. The enzymes were selected from the enzyme portfolio of NZYTech Lda. (Portugal), based on their potential processive activity. Ten enzymes 
are classified in the glycoside hydrolase family 9 (GH9), two in GH48, one from GH6, and one from GH5 family. The percentage of cellobiose $(\mathrm{C} 2)$ out of the total products released from the hydrolysis of three polysaccharides with different cellulose crystallinity, namely $\mathrm{CMC}$, PASC and Avicel, is summarized in Table 1. The complete product profile, including glucose $(C 1)$, cellotriose $(C 3)$, cellotetraose $(C 4)$, cellopentaose $(C 5)$, as well as the $\%$ cellulose conversion, is described in Additional file 1: Table S1. According to the results, most of the enzymes produce significant amounts of COS from all three substrates, while the production of glucose (if any) is relatively low. No product release (DP 1-5) was detected by the activity of $\mathrm{CcCel9J}$, whereas the total conversion of cellulose into soluble oligosaccharides was higher in the case of $C t$ Cbh $5 \mathrm{~A}, \mathrm{PaCbh} 6 \mathrm{~A}$ and $C c$ Cel9A.

The estimation of degree of processivity for each enzyme, also shown in Table 1 , was based on the release of $C 2$ and $C 3$ products. $P a C b h 6 \mathrm{~A}, C c \mathrm{Cel} 9 \mathrm{~A}$ and $C t$ Cbh5A exhibited the highest selectivity among other enzymes, with $\mathrm{PaCbh} 6 \mathrm{~A}$ and $\mathrm{CcCel9A}$ to release higher amounts of $\mathrm{C} 2$ as the substrate crystallinity increases.

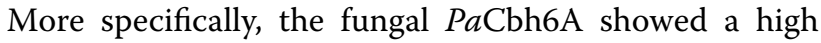
degree of processivity that was approximately 2.5 times higher on Avicel rather than amorphous CMC. These three biocatalysts were first selected as the most promising enzymes to be included in the enzyme cocktail for the production of cellobiose from lignocellulosic materials. $C c$ Cel48A, CtCel9A, CtCbh9A, CcCel9M, CcCel9R, $C s \mathrm{Cbh} 48 \mathrm{~A}, C c \mathrm{Cel} 9 \mathrm{Q}$ and $R f C e l 9 \mathrm{~A}$ did not produce only cellobiose but also $C 3-C 5$ products, thus suggesting that they performed random cleavages along the cellulosic molecule. Others, like CtCbh5A, CtCel9B, PaCbh6A, $C c \mathrm{Cel} 9 \mathrm{~W}$ and $C c$ Cel9A, are recognized as enzymes with exo-activity, as they release $C 2$ and $C 3$ with no presence of $\mathrm{C} 4$ or $\mathrm{C} 5$. Moreover, they exhibit the higher degree of processivity among other enzymes tested, except for CcCel9W.

The results of the activity tests of the enzymes on organosolv-pretreated birch and spruce are shown in Table 2 and Additional file 1: Table S2. The results regarding the total product profile and the relative proportion of cellobiose released are similar to those observed for the pure cellulosic substrates for enzymes CtCbh5A, CtCel9B, PaCbh6A, CcCel9W, CcCel9M, CcCel9J, CcCel9Q. CtCbh5A, PaCbh6A, CcCel9M, CcCel9A exhibit the highest activity on birch (both B1 and B2) and spruce, while $\mathrm{CsCbh} 48 \mathrm{~A}$ also releases a high amount of oligosaccharides from spruce. CtCel9A and RfCel9A were active only on spruce. CcCel48A exhibits a sharp increase in both cellobiose yield and the degree of processivity value. $C t C e l 9 \mathrm{~A}$ and $C t$ Cbh9A do not seem active on these substrates, while $C c \mathrm{Cel} 9 \mathrm{M}$ and $C s \mathrm{Cbh} 48 \mathrm{~A}$ release much lower amount of $C 2$ than in pure substrates. The different specificity and mode of action regarding the release of oligosaccharides can be attributed to the different crystallinity and overall properties of the substrates. The degree of processivity value for the enzymes $C c \mathrm{Cel} 9 \mathrm{~W}$, $C s \mathrm{Cbh} 48 \mathrm{~A}$ and $C c \mathrm{Cel} 9 \mathrm{Q}$ is higher when acting on lignocellulosic biomass compared to the CMC, PASC and Avicel.

Table 1 Relative proportion of cellobiose out of the total products released from the hydrolysis of CMC, PASC and Avicel and calculated degree of processivity of various cellulases used in this study

\begin{tabular}{|c|c|c|c|c|c|c|}
\hline \multirow[t]{2}{*}{ Enzyme name } & \multicolumn{2}{|l|}{ CMC } & \multicolumn{2}{|l|}{ PASC } & \multicolumn{2}{|l|}{ Avicel } \\
\hline & $\%$ cellobiose & $\begin{array}{l}\text { Degree } \\
\text { of processivity }(P)\end{array}$ & $\%$ cellobiose & $\begin{array}{l}\text { Degree } \\
\text { of processivity }(P)\end{array}$ & $\%$ cellobiose & $\begin{array}{l}\text { Degree } \\
\text { of processivity } \\
(P)\end{array}$ \\
\hline 1. CcCel48A & 49.4 & 1.9 & 57.2 & 2.5 & 61.6 & 1.9 \\
\hline 2. $\mathrm{CtCbh} 5 \mathrm{~A}$ & 78.3 & 4.7 & 71.1 & 2.4 & 79 & 3.6 \\
\hline 3. CtCel9A & 33.7 & 1.8 & 47.7 & 1.4 & 52.2 & 2.2 \\
\hline 4. CtCbh9A & 44.8 & 0.8 & 0 & 0.7 & 0 & - \\
\hline 5. CtCel9B & 70.8 & 2.6 & 75.4 & 3.8 & 70.1 & 2.3 \\
\hline 6. $\mathrm{PaCbh6 \textrm {A }}$ & 85.9 & 5.2 & 87.2 & 7.0 & 92.5 & 12.0 \\
\hline 7. CcCel9W & 53.6 & 1.1 & 40.2 & 0.8 & 50.7 & 0.9 \\
\hline 8. CcCel9M & 25.2 & 0.8 & 30 & 0.5 & 36 & 0.4 \\
\hline 9. CcCel9R & 14.8 & 0.4 & 16 & 0.6 & 30 & 0.5 \\
\hline 10. CcCel9A & 81.4 & 3.8 & 80.7 & 3.7 & 85.2 & 5.5 \\
\hline 11. CsCbh48A & 59.5 & 2.1 & 70.2 & 3.1 & 75.8 & 3 \\
\hline 12. CcCel9J & 0 & - & 0 & - & 0 & - \\
\hline 13. CcCel9Q & 59 & 1.8 & 60.1 & 1.6 & 74 & 2.8 \\
\hline 14. RfCel9A & 44.2 & 1.9 & 35.5 & 1.6 & 56.9 & 2.7 \\
\hline
\end{tabular}


Table 2 Relative proportion of cellobiose out of the total products released from the hydrolysis of lignocellulosic biomass and calculated degree of processivity of enzymes

\begin{tabular}{|c|c|c|c|c|c|c|}
\hline \multirow[t]{2}{*}{ Enzyme name } & \multicolumn{2}{|l|}{ Birch (B1) } & \multicolumn{2}{|l|}{ Birch (B2) } & \multicolumn{2}{|l|}{ Spruce (S1) } \\
\hline & $\%$ cellobiose & $\begin{array}{l}\text { Degree } \\
\text { of processivity }(P)\end{array}$ & $\%$ cellobiose & $\begin{array}{l}\text { Degree } \\
\text { of processivity }(P)\end{array}$ & $\%$ cellobiose & $\begin{array}{l}\text { Degree } \\
\text { of processivity } \\
(P)\end{array}$ \\
\hline 1. CcCel48A & 90.9 & 10 & 85 & 14.2 & 73.6 & 4.7 \\
\hline 2. CtCbh5A & 77.6 & 3 & 78.5 & 2.8 & 81 & 3.4 \\
\hline 3. CtCel9A & 0 & - & 0 & - & 58 & 1.9 \\
\hline 4. CtCbh9A & 0 & 0 & 1.5 & 0 & 0 & 0 \\
\hline 5. CtCel9B & 76.6 & 3.3 & 71.2 & 2.4 & 59.6 & 2 \\
\hline 6. PaCbh6A & 94.9 & 18.6 & 92.3 & 11.1 & 92.1 & 11.7 \\
\hline 7. CcCel9W & 67.2 & 4 & 79.6 & 6.1 & 63.4 & 2.3 \\
\hline 8. CcCel9M & 41.1 & 0.1 & 61.4 & 0.8 & 42.2 & 0.2 \\
\hline 9. CcCel9R & 82.9 & 6.6 & 79.5 & 6.9 & 26.6 & 1 \\
\hline 10. CcCel9A & 80.2 & 4.3 & 84.6 & 5.1 & 86.8 & 5.8 \\
\hline 11. CsCbh48A & 87.4 & 6.7 & 87.8 & 8.1 & 86.2 & 5.9 \\
\hline 12. CcCel9J & 0 & - & 0 & - & 0 & - \\
\hline 13. CcCel9Q & 63.8 & 3.3 & 73.8 & 4.2 & 77.2 & 2.9 \\
\hline 14. RfCel9A & 0 & - & 0 & - & 53.9 & 3.5 \\
\hline
\end{tabular}

\section{ii. Kinetics of hydrolysis of oligosaccharides}

In order to estimate the catalytic efficiency of the processive enzymes on the soluble oligosaccharides with DP ranging from 5 to 8 , a kinetics study was performed, and the catalytic efficiency $k_{\mathrm{cat}} / K_{\mathrm{m}}$ was calculated. According to the results depicted in Table 3, different activity and cleavage pattern of each enzyme are noticed as the polymerization degree (DP) increases. Particularly, there is a class of enzymes that the catalytic efficiency is increased together with the increase in the oligosaccharide DP (CcCel48A, CtCbh5A, PaCbh6A, CcCel9W, CsCbh48A, CcCel9Q, RfCel9A), while other enzymes show decreased activity as the number of glucose units increases (CtCel9A, CtCbh9A, CcCel9R). On the other hand, there are also some enzymes that their activity remains same despite the increase in the DP (CtCel9B,

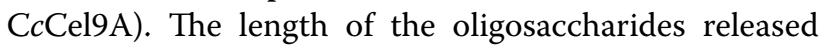
from the activity of $C c$ Cel48A shows that the enzyme is very active on $C 7$ and $C 8$, and, after the first cleavage (releases $C 2$ or $C 3$ ), it prefers to cleave another $C 8$ molecule rather than further cleave $C 5$ to $C 2$ and $C 3$. CtCbh5A, CcCel9W, CsCbh48A, CcCel9Q and RfCel9A exhibit similar catalytic efficiency on oligosaccharides with DP 5-7, while it is much higher for $C 8 . \mathrm{PaCbh} 6 \mathrm{~A}$ prefers $C 7$ and $C 8$ rather than $C 5$ and $C 6$, while $C t$ Cel9A, $C t$ Cbh9A and $C c$ Cel9R have very low activity on $C 7$ and C8. CtCbh5A, PaCbh6A, CcCel9W and CcCel9M showed the highest catalytic efficiency and were those that also exhibit the highest activity yields on the polysaccharidic substrates.
Summarizing all the results from the activity tests on cellulosic polysaccharides (CMC, PASC, Avicel), oligosaccharides and lignocellulosic materials, the enzymes $\mathrm{CtCbh} 5 \mathrm{~A}$ and $\mathrm{PaCbh} 6 \mathrm{a}$ best satisfy the requirements for high activity and degree of processivity, high cellobiose production and low glucose production. Thus, these enzymes were chosen as the most suitable for the construction of an enzymatic cocktail together with the other key enzymes for cellobiose production. CtCbh5A, when added to the cocktail, rather decreased the cellobiose yield instead of acting synergistically with other processive enzymes (data not shown), and therefore, it was not included in any further study. On the contrary, the activity tests that were performed for the $\mathrm{PaCbh} 6 \mathrm{~A}$ showed that when this enzyme was added to a cocktail, the cellobiose yield increased. As a result, PaCbh6A was considered as the most promising to be included in the experimental design for birch and spruce biomass hydrolysis in order to determine the optimal enzyme combination for the maximum cellobiose yield.

\section{Optimization experiments and construction of a defined enzyme cocktail}

Preliminary experiments were run in order to identify the upper and lower limits for each enzyme relative proportion in the cocktail. The preliminary results with the recombinant enzymes enabled the selection of the appropriate limits of the relative abundances of the enzymes for the experimental design. The results, as depicted in Table 4, showed that for all the lignocellulosic substrates 
Table 3 Estimation of $\boldsymbol{k}_{\mathrm{cat}} / K_{\mathrm{m}}$ and product profile of the processive cellulases on cello-oligosaccharides with DP 5-8

\begin{tabular}{|c|c|c|c|c|c|c|c|c|}
\hline \multirow[t]{2}{*}{ Enzyme name } & \multicolumn{4}{|c|}{$k c a t / K m\left(\min ^{-1} \mathrm{M}^{-1}\right)$} & \multicolumn{4}{|c|}{ Mode of action $^{a}$} \\
\hline & C5 & $C 6$ & $C 7$ & $C 8$ & C5 & C6 & $C 7$ & $C 8$ \\
\hline 1. CcCel48A & $1.37 \times 10^{3}$ & $2.89 \times 10^{3}$ & $4.35 \times 10^{3}$ & $4.41 \times 10^{3}$ & $C 3+C 2$ & $C 4$ to $C 2$ & $C 4$ to $C 1$ & $C 5$ to $C 1$ \\
\hline 2. $C t C b h 5 A$ & $8.18 \times 10^{3}$ & $8.15 \times 10^{3}$ & $8.3 \times 10^{3}$ & $9.01 \times 10^{3}$ & $C 3+C 2$ & $C 4$ to $C 2$ & $C 4$ to $C 2$ & $\mathrm{C} 6$ to $\mathrm{C}_{1}$ \\
\hline 3. CtCel9A & $6.45 \times 10^{2}$ & $6.76 \times 10^{2}$ & $2.55 \times 10^{2}$ & $9.3 \times 10^{1}$ & $C 3+C 2$ & $C 4$ to $C 2$ & $C 4$ to $C 2$ & $C 5$ to $C 2$ \\
\hline 4. CtCbh9A & $7.46 \times 10^{2}$ & $7.61 \times 10^{2}$ & $2.01 \times 10^{2}$ & $2.36 \times 10^{2}$ & $\mathrm{C} 4$ to $\mathrm{Cl}$ & $C 4$ to $C 2$ & $C 4$ to $C 2$ & $C 5$ to $C 2$ \\
\hline 5. CtCel9B & $1.71 \times 10^{3}$ & $1.56 \times 10^{3}$ & $1.59 \times 10^{3}$ & $1.88 \times 10^{3}$ & $C 3+C 2$ & $C 4$ to $C 2$ & $C 5$ to $C 2$ & C6 to $C 2$ \\
\hline 6. PaCbh6A & $5.13 \times 10^{3}$ & $3.46 \times 10^{4}$ & $8.87 \times 10^{4}$ & $8.11 \times 10^{4}$ & $C 3+C 2$ & $C 4$ to $C 2$ & $C 4$ to $C 2$ & $C 5$ to $C 2$ \\
\hline 7. ccCel9w & $1.13 \times 10^{3}$ & $8.74 \times 10^{3}$ & $2.18 \times 10^{4}$ & $2.86 \times 10^{4}$ & $C 3+C 2$ & $C 4$ to $C 2$ & $C 4$ to $C 2$ & $C 5$ to $C 2$ \\
\hline 8. CcCel9M & $2.99 \times 10^{4}$ & $2.52 \times 10^{4}$ & $3.17 \times 10^{4}$ & $2.78 \times 10^{4}$ & $\mathrm{C} 4+\mathrm{C}_{1}$ & $\mathrm{C} 4+\mathrm{C} 2$ & $C 4$ to $C 2$ & $C 5$ to $C 2$ \\
\hline 9. CcCel9R & - & $2.04 \times 10^{3}$ & $1.23 \times 10^{3}$ & $8.51 \times 10^{2}$ & - & C3 & $C 4+C 3$ & $\mathrm{C} 5$ to $\mathrm{C3}$ \\
\hline 10. CcCel9A & $1.37 \times 10^{3}$ & $1.34 \times 10^{3}$ & $1.34 \times 10^{3}$ & $1.79 \times 10^{3}$ & $\mathrm{C} 4$ to $\mathrm{Cl}$ & $C 4$ to $C 2$ & $C 5$ to $C 2$ & $C 4$ to $C 2$ \\
\hline 11. CsCbh48A & $1.00 \times 10^{3}$ & $1.56 \times 10^{3}$ & $2.97 \times 10^{3}$ & $3.70 \times 10^{3}$ & $C 3+C 2$ & $C 4$ to $C 2$ & $\mathrm{C} 6$ to $\mathrm{C} 1$ & $\mathrm{C} 6$ to $\mathrm{Cl}$ \\
\hline 12. CcCel9J & - & - & - & - & - & - & - & - \\
\hline 13. ccCel9Q & $3.26 \times 10^{3}$ & $3.81 \times 10^{3}$ & $5.04 \times 10^{3}$ & $6.51 \times 10^{3}$ & $C 3+C 2$ & $C 4$ to $C 2$ & $C 4$ to $C 2$ & C6 to $C 2$ \\
\hline 14. RfCel9A & $1.12 \times 10^{2}$ & $1.94 \times 10^{3}$ & $5.77 \times 10^{3}$ & $5.93 \times 10^{3}$ & - & $C 4$ to $C 2$ & $C 5$ to $C 2$ & C6 to $C 2$ \\
\hline
\end{tabular}

a " $C 2+C 3$ " represents the products $C 2$ and $C 3$, while " $C 4$ to $C 1$ " represents a range of products with degree of polymerization varying between 4 and 1 , i.e., from cellotetraose to glucose $(C 4+C 3+C 2+C 1)$

the optimum combination of the enzymes that maximizes the cellobiose yield is same and particularly the combination \#3, which corresponds to 30\% TtEG5, 30\% Tt $\mathrm{LPMO}$ and $40 \% \mathrm{TtCBH7}$. This observation confirms that a relative abundance of all the three enzymes is needed and thus the construction of an enzymatic cocktail provides higher cellobiose yields. The cellobiose yield that is achieved by this enzyme combination for birch is $10.3 \%$ and $13.0 \%$ (\% w/w cellulose conversion into cellobiose) for B1 and B2, respectively. For spruce, the maximum cellobiose yield that is achieved is $8.4 \%$. It can be therefore noticed that B2 gives higher cellobiose yields among the other lignocellulosic substrates, leading to the production of $90.4 \mathrm{mg}$ of cellobiose/g of substrate. In general, spruce gives slightly lower hydrolysis yields which can be attributed to the higher lignin content (14. 9\%) compared to birch (B1: 7.8\%, B4: 7.1\%). Additionally, it should be mentioned that the cellobiose-to-glucose ratio is quite low for B2 compared to B1, while spruce exhibits much higher ratio.

The processive enzyme that was selected to be included in the cocktail, $\mathrm{PaCbh} 6 \mathrm{~A}$, was tested in different relative proportions together with EG5, TtCBH7, TtLPMO and $T t$ EG7. The four core enzymes (EG5, CBH7, TtLPMO and $\mathrm{PaCbh6A)}$ participated in the $95 \%$ of the enzyme mixture, while EG7 consisted 5\% of the enzyme mixture and was added on a fixed proportion in all experimental runs. The $\% \mathrm{w} / \mathrm{w}$ cellulose conversion into cellobiose was used as the response factor to estimate the hydrolysis rate. All data are summarized in Additional file 1: Table S3. In the

Table 4 Hydrolysis data from preliminary experiments with EG5, MtCBH7 and TtLPMO

\begin{tabular}{|c|c|c|c|c|c|c|c|c|c|c|c|c|}
\hline \multirow[t]{2}{*}{ Run } & \multirow{2}{*}{$\begin{array}{l}\text { EG5 } \\
\%\end{array}$} & \multirow{2}{*}{$\begin{array}{l}\text { TtLPMO } \\
\%\end{array}$} & \multirow{2}{*}{$\begin{array}{l}\text { MtCBH7 } \\
\%\end{array}$} & \multirow{2}{*}{$\begin{array}{l}\text { C2\% } \\
\text { B1 }\end{array}$} & \multirow[t]{2}{*}{$C 1 \%$} & \multirow{2}{*}{$\begin{array}{l}\text { C2\% } \\
\text { B2 }\end{array}$} & \multirow[t]{2}{*}{$C 1 \%$} & \multirow{2}{*}{$\begin{array}{l}\mathrm{C} 2 \% \\
\mathrm{~S} 1\end{array}$} & \multirow[t]{2}{*}{$C 1 \%$} & \multicolumn{3}{|c|}{$C 2 / C 1$} \\
\hline & & & & & & & & & & B1 & B2 & S1 \\
\hline 1 & 1 & 0 & 0 & 5.97 & 0.32 & 4.69 & 0.94 & 5.7 & 0.28 & 18.8 & 5 & 20.4 \\
\hline 2 & 0 & 0 & 1 & 5.98 & 1.05 & 7.87 & 2.58 & 4.15 & 0.29 & 5.7 & 3 & 14.3 \\
\hline 3 & 0.3 & 0.3 & 0.4 & 10.3 & 1.58 & 13.02 & 2.62 & 8.39 & 0.44 & 6.5 & 5 & 18.9 \\
\hline 4 & 0.4 & 0.1 & 0.5 & 9.91 & 1.38 & 11.16 & 2.51 & 5.64 & 0.32 & 7.2 & 4.5 & 17.5 \\
\hline 5 & 0.3 & 0.1 & 0.6 & 7.41 & 1.43 & 12.01 & 2.64 & 4.75 & 0.32 & 5.2 & 4.6 & 14.8 \\
\hline 6 & 0.5 & 0 & 0.5 & 8.68 & 1.55 & 10.12 & 2.44 & 4.89 & 0.28 & 5.6 & 4.1 & 17.3 \\
\hline 7 & 0 & 0.2 & 0.8 & 9.06 & 1.86 & 10.1 & 2.75 & 4.47 & 0.34 & 4.9 & 3.7 & 13.3 \\
\hline 8 & 0 & 0.3 & 0.7 & 8.07 & 1.38 & 7.69 & 2.08 & 3.49 & 0.26 & 5.9 & 3.7 & 13.2 \\
\hline 9 & 0.8 & 0.2 & 0 & 6.35 & 0.52 & 5.98 & 1.14 & 5.39 & 0.29 & 12.3 & 5.3 & 18.3 \\
\hline 10 & 0.7 & 0.3 & 0 & 5.63 & 0.38 & 6.13 & 1.25 & 6.33 & 0.36 & 15 & 4.9 & 17.5 \\
\hline
\end{tabular}


case of birch, the hydrolysis data for $24 \mathrm{~h}$ of reaction were fitted to a quadratic model $\left(R^{2}=0.7404, p=0.0434\right)$; a similar model was also used for the case of $48 \mathrm{~h}$ of hydrolysis $\left(R^{2}=0.8071, p\right.$ value $\left.=0.0124\right)$ (Additional file 1 : Table S4). Optimization prediction targeting the maximal release of cellobiose for both 24 and $48 \mathrm{~h}$ generated a ternary enzyme mixture comprised of $20 \%$ EG5, 43\% CBH7, 22\% TtLPMO, 10\% PaCbh6a and 5\% EG7. The theoretical cellobiose yield was predicted to be $21.86 \% \mathrm{w} / \mathrm{w}$ cellulose conversion. As depicted in the ternary plots in Additional file 1: Figure S1, CBH7 is the key enzyme for hydrolysis for both early and late stages of reaction, while the contribution of LPMO and EG5 is of pivotal importance. Addition of PaCbh6A and EG7 at lower percentage favors the release of cellobiose, by comparing the results with the preliminary results in Table 4 . The cellobiose yield that was predicted from the optimal combination was verified experimentally. It was shown that this enzyme mixture leaded to $22.3 \% \mathrm{w} / \mathrm{w}$ cellulose conversion to cellobiose; this value was slightly higher than the one predicted.

Similarly, for the hydrolysis of spruce biomass, quadratic model was used for analyzing the data after $24 \mathrm{~h}$ $\left(R^{2}=0.9072, p\right.$ value $\left.=0.0004\right)$ and $48 \mathrm{~h}$ of hydrolysis $\left(R^{2} 0.8711, p\right.$ value $\left.=0.0008\right)$ (Additional file 1 : Table S4). Optimization prediction generated a ternary enzyme mixture comprised of 35\% EG5, 45\% CBH7, 10\% TtLPMO, 10\% PaCbh6a and 5\% EG7, with a theoretical yield of $19.6 \% \mathrm{w} / \mathrm{w}$ cellulose conversion into cellobiose. CBH7 and EG5 activities are crucial for the hydrolysis, as shown as these enzymes constitute $75 \%$ of the total mixture. The plots at Additional file 1: Figure S2 reveal that EG5 is necessary at the initial stage of hydrolysis (according to data at $24 \mathrm{~h}$ ), while $\mathrm{CBH} 7$ is the key enzyme for maximizing cellobiose at $48 \mathrm{~h}$. The experimental yield of the optimal combination was $19.1 \% \mathrm{w} / \mathrm{w}$ cellulose conversion. After optimization and experimental verification of their performance, the optimal enzyme mixtures that maximize the cellobiose production were employed for the scale-up reaction and production of COS.

\section{Nanofiltration studies}

In order to choose the best membrane to remove glucose from the hydrolysate, screening of five different nanofiltration membranes was performed. The effect of different parameters was tested for evaluating the performance of each membrane regarding the best separation of cellobiose/glucose.

\section{i. Water permeability}

The average water permeabilities $\left(L_{\mathrm{p}}\right)$ of all the membranes were calculated with Eq. 5 and are depicted in Additional file 1: Table S5. The loss of initial water permeability during the nanofiltration trials was found to be 1 unit for all the membranes (data not shown). Hence, membrane fouling did not seem significant in any of the cases.

\section{ii. Effect of feed concentration}

The separation factor for the different membrane systems, given by Eq. 7, is depicted in Table 5. The pure sugars model solution comprised of cellobiose and glucose was tested at different feed concentrations, with a constant molar ratio of cellobiose to glucose equal to 9:1. An increase in the total feed concentration resulted, as expected, in reduced permeate flux (data not shown), as a result of the higher osmotic pressure of the solution. However, increasing the feed concentration did not affect significantly the cellobiose separation factor for all the different pressure conditions applied in this study. In fact, only a slight decrease in the separation factor (within the range of $0.01-0.07$ ) was noticed, which can be attributed to the increase in the total sugar amount. The feed concentration did not exhibit a significant effect neither on the \% retention of cellobiose or on glucose. Only in the case of DL and NF270 membranes, a minor increase in the retention was observed, following the increase in the feed concentration, at the range of $2.4 \%$ for cellobiose (DL membrane) and 6.6\% for glucose (NF270 membrane). In the case of the NFX membrane, the trials were carried out only at 5 bar, as the permeate flux was very high (data not shown) and the separation factor was the lowest (1.00); therefore, this system was not chosen to be used in any further study.

\section{iii. Effect of pressure}

The effect of pressure on the cellobiose separation factor was studied. It was investigated whether an increase in the pressure applied in the nanofiltration vessel could affect the cellobiose/glucose separation factor. The overall conclusion comparing the separation factor values of Table 5 for all the membranes is that higher pressure leads to a decrease in the separation factor. Therefore, the optimal pressure conditions in order to achieve the maximum separation were set up at 10 bar. The membranes that appeared to perform the higher separation at 10 bar were the membrane DL (with a separation factor of 1.14), NF270 (1.12) and TS40 (1.11). For evaluating the membranes' efficiency toward the enhanced separation of cellobiose/glucose system, a comparison of the observed retentions of cellobiose and glucose is necessary. Table 5 depicts the retention data, given by Eq. 6, that refer to the results for the trials that were carried out at room temperature and the optimized pressure of $10 \mathrm{bar}$, except from the NFX membrane where the applied pressure was 5 bar. An efficient separation is achieved by high 
Table 5 Separation factors and sugar retention for all nanofiltration membranes at different feed concentrations of the pure sugar mixture, in various pressure conditions

\begin{tabular}{|c|c|c|c|c|c|c|c|}
\hline \multirow[t]{2}{*}{ Membrane } & \multirow{2}{*}{$\begin{array}{l}\text { Feed concentration } \\
(\mathrm{mg} / \mathrm{mL})\end{array}$} & \multicolumn{4}{|c|}{ Separation factor } & \multicolumn{2}{|c|}{ Retention $(\% \mathrm{w} / \mathrm{w})^{\mathrm{a}}$} \\
\hline & & 5 bar & 10 bar & 15 bar & 20 bar & Cellobiose & Glucose \\
\hline \multirow[t]{2}{*}{ NF270 } & 5 & - & 1.12 & - & 1.03 & 96.3 & 86.4 \\
\hline & 20 & - & 1.05 & - & 1.02 & 97.4 & 93.0 \\
\hline \multirow[t]{2}{*}{$\mathrm{DL}$} & 5 & 1.11 & 1.14 & 1.11 & 1.03 & 86.6 & 76.0 \\
\hline & 20 & - & 1.10 & 1.07 & 1.07 & 89.0 & 81.3 \\
\hline NFX & 5 & - & 1.00 & - & - & 98.8 & 98.5 \\
\hline \multirow[t]{2}{*}{ NFW } & 5 & 1.01 & - & - & - & 64.0 & 63.2 \\
\hline & 20 & 0.96 & - & - & - & 58.1 & 60.4 \\
\hline \multirow[t]{2}{*}{ TS40 } & 5 & - & 1.03 & 1.07 & - & 93.0 & 90.2 \\
\hline & 20 & - & 1.11 & 1.04 & - & 93.6 & 84.4 \\
\hline
\end{tabular}

a The retention of each sugar has been estimated for a pressure of 10 bar, apart from the NFX membrane that was tested only at 5 bar

retention of cellobiose and low retention for glucose. Thus, the membranes that best satisfy this demand are the membrane NF270 (96.3\% for cellobiose and $86.4 \%$ for glucose) and the membrane TS40 (93.6\% for cellobiose and $84.4 \%$ for glucose).

\section{iv. Effect of temperature}

The effect of different temperature conditions on the performance of the membranes that were selected (NF270, TS40) was investigated at $10 \mathrm{bar}$. Another pressure condition was also tested (20 bar) in order to investigate the possibility that temperature and pressure factors have a combined effect on the separation efficiency of the membranes. As shown in Table 6A, applying higher temperature is correlated with a more efficient separation process. The effect of temperature on the separation factor is more clearly presented when the feed concentration is equal to $20 \mathrm{mg} / \mathrm{mL}$, since the separation factor is increased more significantly than in the case of $5 \mathrm{mg} / \mathrm{mL}$ feed concentration. When $20 \mathrm{mg} / \mathrm{mL}$ feed concentration was applied on the NF270 membrane, the separation factor increased at higher temperature conditions; however, the increase was mostly significant when the nanofiltration was performed at $40^{\circ} \mathrm{C}$ (with a separation factor of 1.21), compared to that performed at room temperature (1.05), while it increased slightly at higher temperature $\left(50{ }^{\circ} \mathrm{C}\right.$ and $60{ }^{\circ} \mathrm{C}$ ). When $20 \mathrm{mg} / \mathrm{mL}$ feed concentration was used on the TS40 membrane, the increase in the separation factor was significant when temperature increased from $40{ }^{\circ} \mathrm{C}(1.21)$ to $50{ }^{\circ} \mathrm{C}$ (1.39). Similar to the previous results, it can be noticed that application of higher pressure does not have a favorable effect on separation process; the increase in the separation factor was less significant at 20 bar rather than at 10 bar.
However, according to the results depicted in Table 6B, it can be observed that as the temperature increases, the $\%$ retention for both cellobiose and glucose decreases. Consequently, the selection of the optimal temperature condition depends on both the membrane separation performance and the purpose of the filtration. If higher $\%$ cellobiose retention and elimination of sugar losses are targeted, then nanofiltration should be performed at room temperature $\left(25^{\circ} \mathrm{C}\right)$. If the aim of the study is to achieve the highest separation of the cellobiose/glucose mixture regardless of cellobiose losses, then increasing the operating temperature is suggested. In the case of NF270 membrane, the optimal temperature is $40{ }^{\circ} \mathrm{C}$, while TS40 performs the optimum separation of cellobiose and glucose at $50^{\circ} \mathrm{C}$.

\section{v. Nanofiltration with the enzymatic hydrolysate}

A screening of the membranes was performed with the birch hydrolysate solution in order to evaluate the performance of the membranes toward the separation of cellobiose and glucose and compare the results with those in the case of the pure sugars model solution. The trials were carried out at the optimal pressure condition of $10 \mathrm{bar}$ and at room temperature for all the membranes except for the membrane NFW which showed very low performance on the previous trials from the trials with the model solution. For the membranes that proved to be more efficient (NF270 and TS40), the trials were also carried out at higher temperatures $\left(40,50\right.$ and $\left.60^{\circ} \mathrm{C}\right)$. As shown in Table 7, the results are in accordance with those observed in trials with the pure sugars model solution. Particularly, the membranes with the highest separation factor were NF270 $\left(1.58\right.$ at $\left.40{ }^{\circ} \mathrm{C}\right)$ and TS40 $(1.35$ at $50{ }^{\circ} \mathrm{C}$ ). From the results in Table 7 it can be observed that the retention for both cellobiose and glucose reduced 
Table 6 (A) Separation factor for NF270 and TS40 membrane at different feed concentrations, pressure and temperature conditions. (B) Observed retention for cellobiose and glucose at different feed concentrations and temperatures with the model solution at 10 bar and 20 bar

\begin{tabular}{|c|c|c|c|c|c|c|c|c|c|}
\hline \multirow[t]{3}{*}{ Membrane } & \multirow{3}{*}{$\begin{array}{l}\text { Feed concentration } \\
(\mathrm{mg} / \mathrm{mL})\end{array}$} & \multicolumn{8}{|c|}{ Separation factor } \\
\hline & & \multicolumn{3}{|c|}{10 bar } & \multicolumn{5}{|l|}{20 bar } \\
\hline & & $40^{\circ} \mathrm{C}$ & $50^{\circ} \mathrm{C}$ & $60^{\circ} \mathrm{C}$ & $40^{\circ} \mathrm{C}$ & $50^{\circ} \mathrm{C}$ & $60^{\circ} \mathrm{C}$ & & \\
\hline \multirow[t]{2}{*}{ NF270 } & 5 & 1.32 & 1.32 & 1.31 & 1.02 & 1.09 & 1.15 & & \\
\hline & 20 & 1.21 & 1.26 & 1.36 & 1.10 & 1.08 & 1.29 & & \\
\hline \multirow[t]{2}{*}{ TS40 } & 5 & 1.00 & 1.16 & - & - & - & - & & \\
\hline & 20 & 1.21 & 1.39 & - & - & - & - & & \\
\hline \multicolumn{10}{|l|}{ (B) } \\
\hline \multirow[t]{3}{*}{ Membrane } & Feed concentration & \multicolumn{8}{|c|}{ Retention $^{\mathrm{a}}(\%)$} \\
\hline & & \multicolumn{2}{|l|}{ RT } & \multicolumn{2}{|l|}{$40^{\circ} \mathrm{C}$} & \multicolumn{2}{|l|}{$50^{\circ} \mathrm{C}$} & \multicolumn{2}{|c|}{$60^{\circ} \mathrm{C}$} \\
\hline & & $C 2$ & $C 1$ & $C 2$ & C1 & $C 2$ & C1 & $C 2$ & $C 1$ \\
\hline \multirow[t]{2}{*}{ NF270 } & 5 & 96.3 & 86.4 & 91.4 & 69.2 & 89.1 & 72.6 & 87.6 & 66.8 \\
\hline & 20 & 97.4 & 93.0 & 95.5 & 79.1 & 91.2 & 72.5 & 94.9 & 69.9 \\
\hline \multirow[t]{2}{*}{ TS40 } & 5 & 93.0 & 90.2 & 99.3 & 99.2 & 98.6 & 84.6 & - & - \\
\hline & 20 & 93.6 & 84.4 & 91.3 & 75.5 & 89.3 & 64.3 & - & - \\
\hline
\end{tabular}

$R T$ room temperature

a The retention of each sugar has been estimated for a pressure of $10 \mathrm{bar}$

with the increase in the temperature for membrane NF270, while for TS40 the cellobiose retention increased from $40{ }^{\circ} \mathrm{C}(91.2 \%)$ to $50{ }^{\circ} \mathrm{C}(94.6 \%)$. Similar conclusions are made regarding the most efficient separation of cellobiose/glucose as before for the pure sugar mixture. If higher cellobiose retention is required, the optimal operating temperature is $25{ }^{\circ} \mathrm{C}$, while for achieving the highest separation, the optimal temperature is $40{ }^{\circ} \mathrm{C}$ for membrane NF270 and $50^{\circ} \mathrm{C}$ for membrane TS40.

\section{Scale-up reaction and product recovery}

A scale-up reaction with a total volume of $100 \mathrm{~mL}$ was carried out using the optimized enzymatic combinations that were determined for each substrate (birch B1 and spruce S2). The main target was the maximum production of cellobiose, the concentration and product recovery out of the hydrolysate and, finally, the tests as a carbohydrate source for several probiotic strains. TFF and nanofiltration method was applied as a product recovery method, even though during the filtration, a slight amount of cellobiose amounts can be removed in the permeate. Figure 1 represents the overall procedure for the production of cellobiose from birch, as well as the product yield and recovery in each stage. A total amount of $989 \mathrm{mg}$ of cellobiose was produced from the enzymatic hydrolysis of $6 \mathrm{~g}$ of initial biomass, corresponding to $164 \mathrm{mg}$ of cellobiose/g of substrate, while after filtration,
$787 \mathrm{mg}$ of the final product remained. The nanofiltration step resulted in the removal of a great amount of glucose, leading to a final cellobiose-to-glucose ratio of 21.1. In the case of spruce, the enzymatic hydrolysis yielded 128 cellobiose/g of substrate with a 17.4 cellobiose: glucose ratio, while after nanofiltration, the final product was comprised of $651 \mathrm{mg}$ cellobiose and $32 \mathrm{mg}$ glucose (20.2 cellobiose: glucose ratio). The products were freeze-dried and used for evaluation of their prebiotic potential.

\section{Evaluation of COS prebiotic activity}

i. Growth potential of Bifidobacteria and Lactobacilli strains on pure cellobiose

The ability of different bacterial probiotic strains to utilize pure cellobiose as carbon source was studied and compared to their growth rate on glucose. The results, as evaluated by the increase in the optical density $\left(\mathrm{OD}_{600}\right)$ and the carbohydrate accumulation, are summarized in Table 8 and depicted in Fig. 2. Cultivation in the absence of any carbon substrate did not show any growth of the probiotic strains. Only one of the Bifidobacteria strains, namely $B$. adolescentis, showed a slight growth on culture media supplemented with $2 \% \mathrm{w} / \mathrm{v}$ cellobiose. The growth rate of $B$. adolescentis on cellobiose was $\mu=0.014 \mathrm{~h}^{-1}$ which was considered very low compared to that when grown on glucose $\left(\mu=0.107 \mathrm{~h}^{-1}\right)$, also verified by the low value of the 
Table 7 (A) Separation factor and (B) sugar retention for different membranes and temperature conditions with the enzymatic hydrolysate at 10 bar

\begin{tabular}{|c|c|c|c|c|c|c|c|c|}
\hline NF270 & 1.06 & 1.58 & 1.26 & 1.32 & & & & \\
\hline $\mathrm{DL}$ & 1.04 & - & - & - & & & & \\
\hline NFX & 1.01 & - & - & - & & & & \\
\hline TS40 & - & 1.13 & 1.35 & - & & & & \\
\hline \multicolumn{9}{|l|}{ (B) } \\
\hline \multirow[t]{3}{*}{ Membrane } & \multicolumn{8}{|c|}{ Retention $^{\mathrm{a}}(\%)$} \\
\hline & \multicolumn{2}{|l|}{ RT } & \multicolumn{2}{|l|}{$40^{\circ} \mathrm{C}$} & \multicolumn{2}{|c|}{$50^{\circ} \mathrm{C}$} & \multicolumn{2}{|c|}{$60^{\circ} \mathrm{C}$} \\
\hline & $C 2$ & $C 1$ & $C 2$ & C1 & $C 2$ & $C 1$ & $C 2$ & $C 1$ \\
\hline NF270 & 98.3 & 92.8 & 88.3 & 55.9 & 88.9 & 70.5 & 83.9 & 63.5 \\
\hline $\mathrm{DL}$ & 88.2 & 84.6 & - & - & - & - & - & - \\
\hline NFX & 99.8 & 98.4 & - & - & - & - & - & - \\
\hline TS40 & - & - & 91.2 & 80.9 & 94.6 & 69.9 & - & - \\
\hline
\end{tabular}

a The retention of each sugar has been estimated for a pressure of $10 \mathrm{bar}$

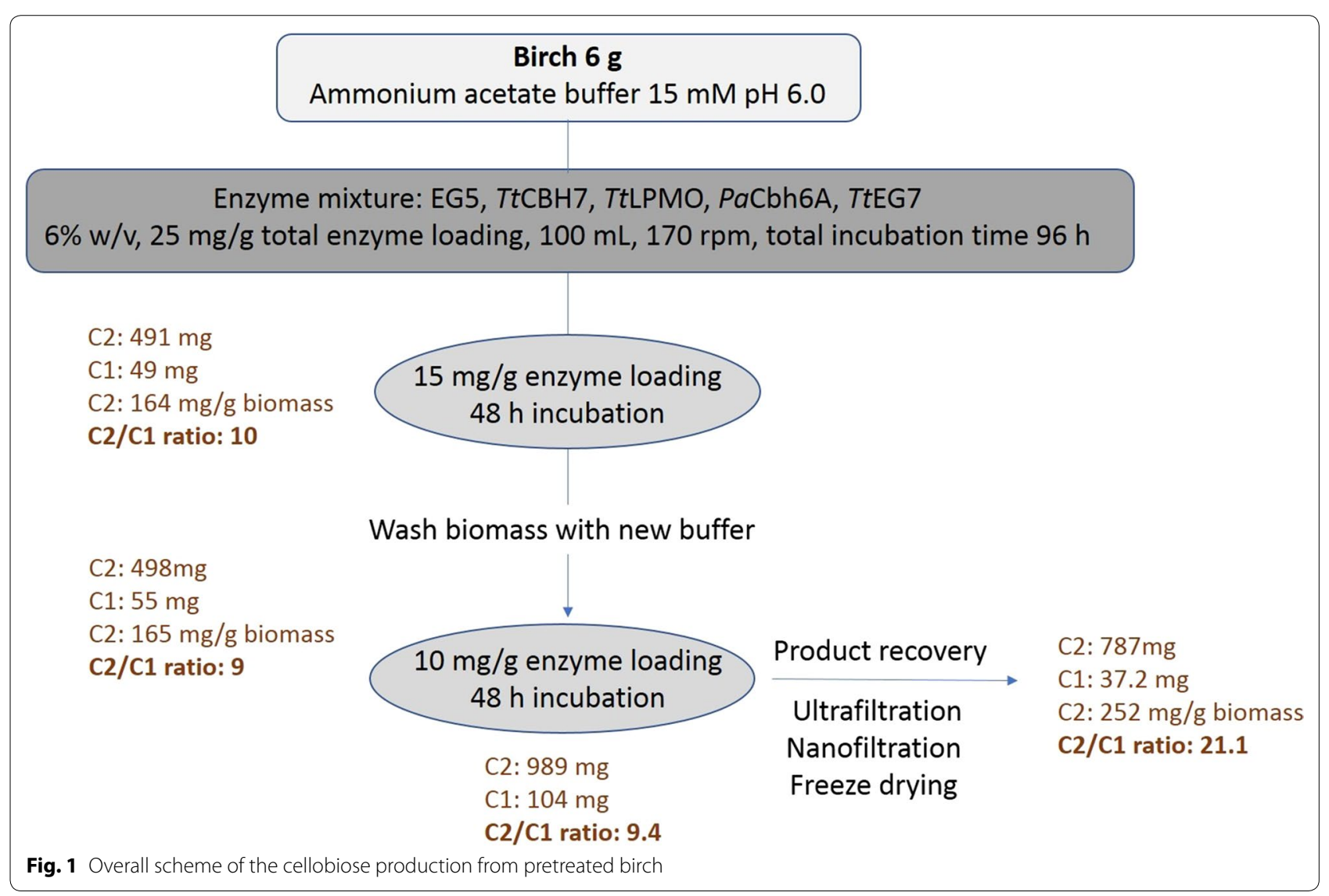


final optical density of the culture $\left(\mathrm{OD}_{600}=1.06 \pm 0.07\right)$. Therefore, this strain was not chosen for further studies to evaluate the prebiotic potential of lignocellulosicderived COS. Among the Lactobacilli strains, two of them (L. gasseri and L. plantarum) could efficiently grow on cellobiose. L. gasseri strain can utilize both carbon sources which is demonstrated by the similar growth rates in cellobiose and glucose $\left(\mu=0.212 \mathrm{~h}^{-1}\right)$ and exhibits a relatively high growth in cellobiose (final $\left.\mathrm{OD}_{600}=1.56 \pm 0.03\right)$. L. plantarum appeared to be the most promising probiotic strain for further studies, as it shows the highest growth rate in cellobiose $\left(\mu=0.407 \mathrm{~h}^{-1}\right)$ and a final $\mathrm{OD}_{600}=5.35 \pm 0.04$. Moreover, in this study, it was the only strain that consumed the total carbohydrate content within the first $25 \mathrm{~h}$ of fermentation, as shown in Fig. 2c). The growth rates of all the strains were lower when cultured in cellobiose than when cultured in glucose. Lactic acid is the only metabolite that is produced by both $L$. gasseri and $L$. plantarum when grown on cellobiose, as depicted in Table 9, while no production of any short chain fatty acid (acetic, propionic, butyric acid) was detected.

\section{ii. Growth potential of Lactobacillus strains on plant-derived cos}

The Lactobacillus strains that were able to utilize pure cellobiose as carbon source were used for further testing the prebiotic effect of the plant-derived

Table 8 Cellobiose utilization by Bifidobacterium and Lactobacillus strains

\begin{tabular}{llll}
\hline Bifidobacteria strains & Cellobiose growth & Lactobacilli strains & Cellobiose growth \\
\hline B. adolescentis DSM 20083 & + & L. gasseri DSM 20077 & ++ \\
B. longum DSM 20219 & - & L. plantarum ATCC 8014 & ++++ \\
B. animalis subsp. lactis & - & L. reuteri DSM 20016 & -
\end{tabular}

A minus sign (-) indicates that final $\mathrm{OD}_{600}<0.6$, + indicates final $\mathrm{OD}_{600}=0.6-1,++$ indicates final $\mathrm{OD}_{600}=1-2,+++$ indicates final $\mathrm{OD}_{600}=2-5$, and ++++ indicates final $\mathrm{OD}_{600}>5$

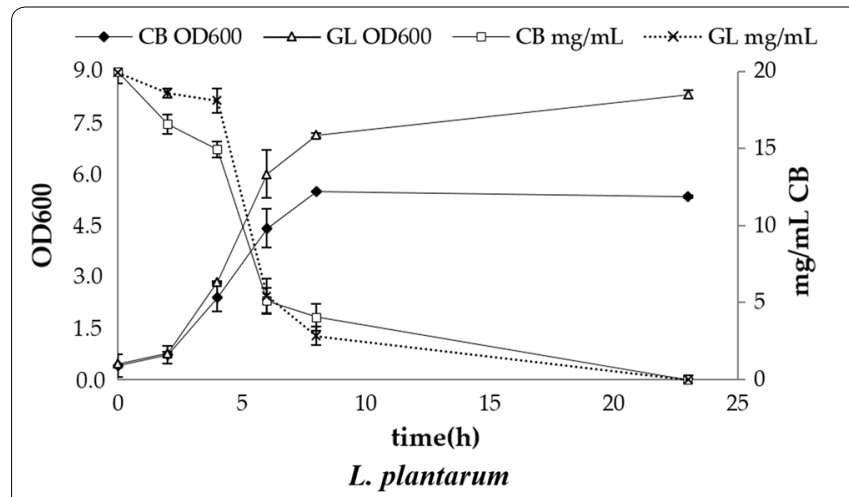

$\mathbf{a}$

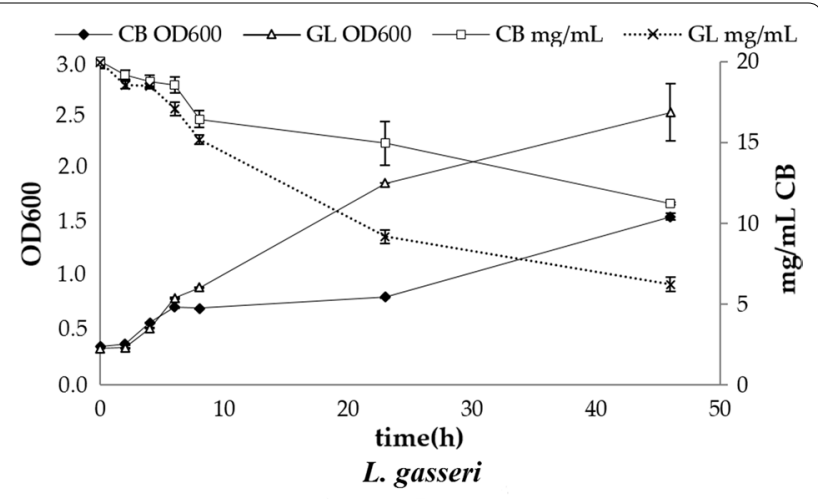

b

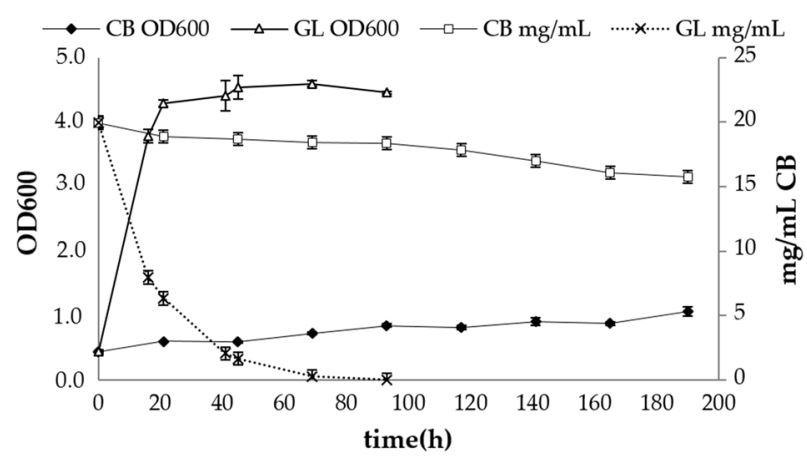

B. adolescentis

c

Fig. 2 Growth curve and carbohydrate consumption of a L. plantarum, b L. gasseri and c B. adolescentis grown on culture media supplemented with $2 \%(\mathrm{w} / \mathrm{v})$ cellobiose and $2 \%(\mathrm{w} / \mathrm{v})$ glucose 
cello-oligosaccharides (COS). The results showed that both strains are able to grow on birch-derived COS as shown in Fig. 3 by the increase in the optical density value and the consumption of the cellobiose content. The most effective strain was L. plantarum, with a growth rate of $\mu=0.161 \mathrm{~h}^{-1}$, while $L$. gasseri could also utilize this carbon source and grow. In the case of spruce-derived sugars, L. plantarum strain exhibited very slow growth $\left(\mu=0.039 \mathrm{~h}^{-1}\right)$, while $L$. gasseri did not grow at all. Determination of the fermentation products (Table 9) reveals the presence of other sugars existing in the biomass hydrolysate that were not detected by HPLC and can be consumed by L. plantarum, since the amount of the lactic acid produced is much higher than the cellobiose that is consumed. In fact, a low amount of glucose is present, but still the final concentration of lactic acid is much higher. Analysis of hydrolysates with HPAEC-PAD chromatography revealed traces of cellotriose, cellotetraose, as well as some oxidized products; however, it is possible that oligosaccharides with higher DP exist in the hydrolysate and are consumed by the

Table 9 Fermentation metabolites of (A) L. gasseri and (B) L. plantarum upon growth on pure cellobiose, birch and spruce COS-rich hydrolysates

(A)

\begin{tabular}{|c|c|c|c|c|c|c|}
\hline & \multicolumn{6}{|l|}{ L. gasseri } \\
\hline & \multicolumn{2}{|l|}{ Cellobiose } & \multicolumn{2}{|l|}{ Birch } & \multicolumn{2}{|l|}{ Spruce } \\
\hline & $\mathrm{Oh}$ & $26 \mathrm{~h}$ & $\mathrm{Oh}$ & $26 \mathrm{~h}$ & $\mathrm{Oh}$ & $95 \mathrm{~h}$ \\
\hline Cellobiose & $20.0 \pm 1.06$ & $9.3 \pm 0.12$ & $19.6 \pm 2.04$ & $0.0 \pm 0.00$ & $19.3 \pm 0.06$ & $19.2 \pm 0.29$ \\
\hline Lactic acid & $0.33 \pm 0.06$ & $8.53 \pm 0.91$ & $0.2 \pm 0.03$ & $26.5 \pm 1.52$ & $0.2 \pm 0.09$ & $0.5 \pm 0.20$ \\
\hline Acetic acid & $4.03 \pm 0.21$ & $4.07 \pm 0.05$ & $7.9 \pm 1.04$ & $8.0 \pm 0.42$ & $6.6 \pm 0.19$ & $7.2 \pm 0.12$ \\
\hline Propionic acid & $0.93 \pm 0.03$ & $1.03 \pm 0.12$ & $0.8 \pm 0.10$ & $1.3 \pm 0.11$ & $0.7 \pm 0.15$ & $0.8 \pm 0.01$ \\
\hline
\end{tabular}

(B)

\begin{tabular}{|c|c|c|c|c|c|c|}
\hline & \multicolumn{6}{|c|}{ L. plantarum } \\
\hline & \multicolumn{2}{|l|}{ Cellobiose } & \multicolumn{2}{|l|}{ Birch } & \multicolumn{2}{|l|}{ Spruce } \\
\hline & $\mathrm{Oh}$ & $26 \mathrm{~h}$ & $\mathrm{Oh}$ & $26 \mathrm{~h}$ & $\mathrm{Oh}$ & $95 \mathrm{~h}$ \\
\hline Cellobiose & $20.0 \pm 1.51$ & $0.2 \pm 0.00$ & $19.8 \pm 1.69$ & $0.0 \pm 0.00$ & $19.9 \pm 0.76$ & $10.8 \pm 1.25$ \\
\hline Lactic acid & $0.4 \pm 0.01$ & $21.8 \pm 2.85$ & $0.3 \pm 0.05$ & $28.0 \pm 2.67$ & $0.3 \pm 0.00$ & $21.1 \pm 1.67$ \\
\hline Acetic acid & $4.2 \pm 0.15$ & $3.9 \pm 0.71$ & $7.9 \pm 0.92$ & $8.4 \pm 0.91$ & $6.9 \pm 0.25$ & $8.8 \pm 1.61$ \\
\hline Propionic acid & $0.9 \pm 0.01$ & $0.9 \pm 0.03$ & $0.8 \pm 0.09$ & $1.0 \pm 0.04$ & $0.6 \pm 0.02$ & $1.2 \pm 0.15$ \\
\hline
\end{tabular}

No significant amounts of formic or butyric acid were detected

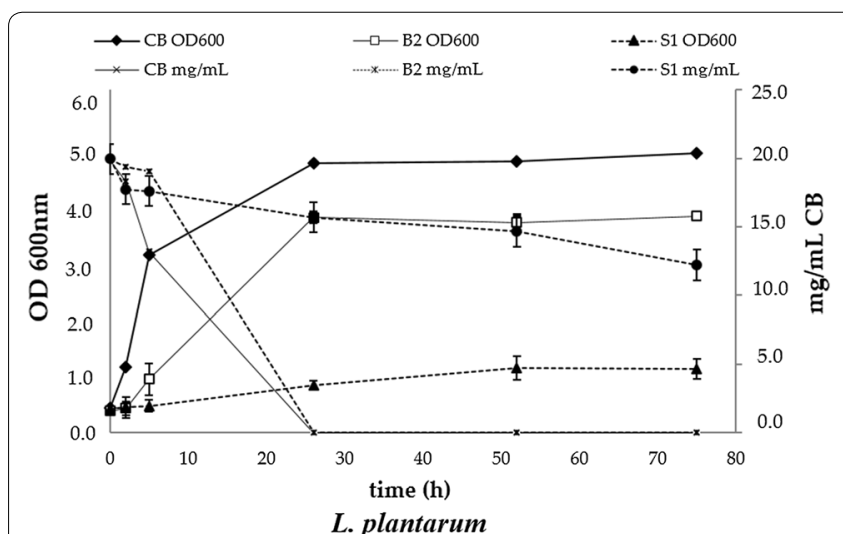

a

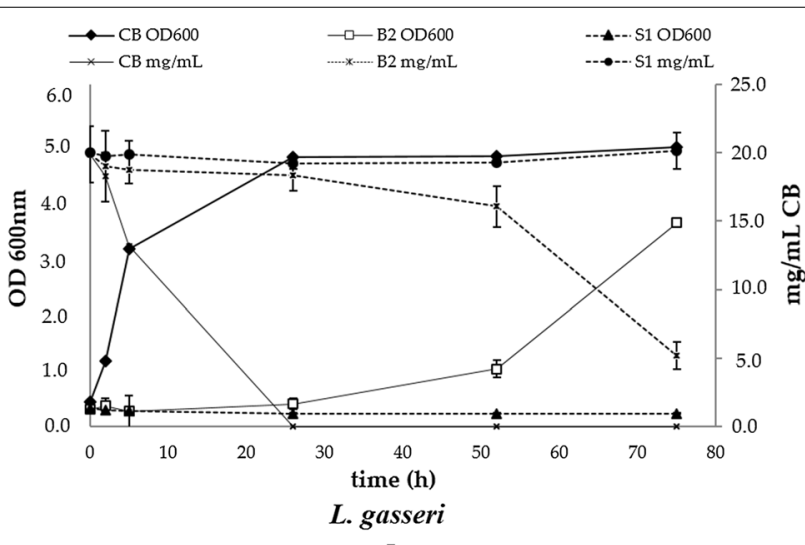

b

Fig. 3 Growth curve and carbohydrate consumption of $\mathbf{a}$ L. plantarum and $\mathbf{b}$ L. gasseri grown on culture media supplemented with biomass hydrolysates at an initial concentration of $2 \%(w / v)$ cellobiose 
bacteria. The same was also observed for the growth of L. gasseri on birch hydrolysate. In a similar way as for the cellobiose substrate, no production of acids was observed. The acetic acid detected at the beginning of the fermentation was originated from the cultivation media and the buffer that was used in the hydrolysis step and was not removed during nanofiltration process.

\section{Discussion}

Forest residues are by nature heterogeneous in composition, size, structure and properties. Thus, the degradability of these materials is different. Birch stem wood contains about $43.9 \% \mathrm{w} / \mathrm{w}$ cellulose, while in the case of spruce this percentage is about $42 \% \mathrm{w} / \mathrm{w}$ [18]. To accomplish the efficient hydrolysis process of different types of lignocellulosic materials, novel lignocellulolytic enzyme mixtures have to be customized. The key enzymes leading to cellobiose production are cellobiohydrolases and processive endoglucanases. The degree of processivity is an estimation of the cleavage per productive binding of the enzyme onto the substrate. Processive enzymes release cellobiose. Throughout the literature, estimation of processivity can be problematic, although we assume that many enzymes will maximize the cellobiose release as a proof of their processive function. Assuming that the first product of an initial cleavage will be either $C 2$ or C3, depending on the configuration of the cellulose molecule in the active site of the enzyme, processive enzymes will perform several cleavages along the same molecule, producing cellobiose as a soluble product, so the ratio of $C 2$ to $C 3$ will increase [18]. The mechanism for processivity has been correlated with structural properties and molecular characteristics of the enzyme, including the interactions of carbohydrate-binding module (CBM) with the substrate $[19,20]$. Moreover, processivity is a rather substrate-specific feature of the enzyme and it differs along with the substrate properties, as it was shown from the results of this study. Some enzymes exhibited a higher degree of processivity on $\mathrm{CMC}$, while others on the highly crystalline Avicel. $\mathrm{PaCbh6a}$ showed a 2.5times higher processivity on Avicel compared to CMC, which has also been reported in the literature for other fungal enzymes [21]. A shift between endo-activity and exo-activity depending on the substrate crystallinity has also been proposed [22].

Screening of different processive cellulases enabled the selection of some promising candidates which were then tested in enzyme cocktails together with processive endoglucanases and cellobiohydrolases for their ability to yield cellobiose. The results showed that $\mathrm{CBH} 7$ and EG5 were the key enzymes for the hydrolysis, but the addition of LPMO and CBH6 increased of product release in a cooperative action of the enzymes that act synergistically. It was found that the efficient hydrolysis of spruce requires a higher amount of $\mathrm{CBH} 7$ and EG5, which has also been reported in the literature [13]. CBH7s are the main catalysts for the production of cellobiose, but severe end-product inhibitory phenomena can occur in their active site; the addition of processive EGs with a wider active site area that are not so susceptible to cellobiose inhibition can boost the hydrolysis and maximize the product release [23].

Scaling-up of the process is always challenging and requires different strategies. The overall yield of the reaction is quite low, but it should be taken into consideration

Table 10 Summary of processive enzymes used in the present study

\begin{tabular}{|c|c|c|c|c|c|}
\hline Number & Enzyme name & Short name & Organism & Architecture & Temperature \\
\hline 1 & Cellobiohydrolase 48A & CcCbh48A & Clostridium cellulolyticum & $\mathrm{GH} 48$ & 37 \\
\hline 2 & Cellobiohydrolase 5A & CtCbh5A & Clostridium thermocellum & CBM3-GH5 & 60 \\
\hline 3 & Cellulase 9A & CtCel9A & Clostridium thermocellum & GH9 & 60 \\
\hline 4 & Cellobiohydrolase 9A & CtCbh9A & Clostridium thermocellum & GH9 & 60 \\
\hline 5 & Cellulase 9B & CtCel9B & Clostridium thermocellum & GH9 & 60 \\
\hline 6 & Cellobiohydrolase 6A & PaCbh6A & Podospora anserina & CBM1-GH6 & 50 \\
\hline 7 & Cellulase 9W & CcCel9W & Clostridium cellulolyticum & GH9 & 37 \\
\hline 8 & Cellulase $9 \mathrm{M}$ & CcCel9M & Clostridium cellulolyticum & GH9 & 37 \\
\hline 9 & Cellulase 9R & Cccel9R & Clostridium cellulolyticum & $\mathrm{GH} 9$ & 37 \\
\hline 10 & Cellulase 9A & CcCel9A & Clostridium cellulovorans & GH9 & 37 \\
\hline 11 & Cellobiohydrolase 48A & CsCbh48A & Clostridium stercorarium & $\mathrm{GH} 48$ & 60 \\
\hline 12 & Cellulase $9 \mathrm{~J}$ & CcCel9s & Clostridium cellulolyticum & GH9 & 37 \\
\hline 13 & Cellulase 9Q & CcCel9Q & Clostridium cellulolyticum & GH9 & 37 \\
\hline 14 & Cellulase 9A & RfCel9A & Ruminococcus champanellensis & GH9 & 50 \\
\hline 15 & Endo-1,4- $\beta$-D-glucanase & EG5 & Talaromyces emersonii & $\mathrm{GH} 5$ & 50 \\
\hline
\end{tabular}


that this is a controlled hydrolysis and there is much of the end-product inhibition, as in nature, microorganisms have been evolved to secrete cocktails that are optimized to perform the complete hydrolysis of the substrate yielding glucose to be used as a carbon source. However, by altering the conditions of the reaction, like multistage hydrolysis together with enzyme recovery and re-usage, we can make the process economically viable, since foodgrade prebiotic oligosaccharides can be produced by cheap and abundant biomass wastes.

The aim of the nanofiltration at the product purification step is the separation of cellobiose and glucose for obtaining a solution potentially pure of cellobiose. This step is especially important for enzymatically produced oligosaccharides. Nanofiltration is an easy maintenance and cost-competitive alternative that can offer promising results. However, cellobiose and glucose molar masses differ only by a factor of 1.9 which inevitably makes the separation process extremely difficult. Study of the effect of the different nanofiltration parameters, such as feed concentration and temperature, revealed that all values corresponding to the cellobiose separation factor are quite low $(<1.5)$, indicating that the cellobiose/glucose system is difficult to separate. An increase in the total feed concentration resulted, as expected, in reduced permeate flux (data not shown), as a result of the higher osmotic pressure of the solution [24]. Moreover, a slight decrease in the separation factor was observed, which can be attributed to the increase in the total sugar amount, which has been also mentioned before [25], even though that study was based on a different system (xylose/glucose). Regarding the effect of temperature, it has been mentioned in previous studies that an increase in the temperature affects the separation process by having an impact not only on the feed solution properties but also on the pore structure of the membrane [26]. By the increase in the temperature, the viscosity of the feed solution was decreased and the permeate flux increased. The latter can be explained by the pore swelling of the membrane [24]. As a result, nanofiltration with different membranes and different operating conditions can offer many possibilities depending on the application that is targeted, either high product recovery (100\% of the initial cellobiose content) or high purity (low glucose yield). In our case, the selection of the most appropriate membrane was done following a stepwise strategy. Data from Table 5 of the revised manuscript show that NSF270 and DL membranes exhibit similar separation factors; however, NSF270 achieves a much higher \% cellobiose retention. In order to prevent the losses, NSF270 was chosen for further studies. TS40 also presented a high \% retention with relatively equal separation factor; therefore, this membrane was also tested on different temperature conditions. Further studies and comparison of TS40 and NSF270 showed that NSF270 outperformed TS40 regarding the separation factor; therefore, this membrane was selected for the scale-up reaction.

In this study, cultivations of six selected bacterial species, three Lactobacilli and three Bifidobacteria strains, using cello-oligosaccharides (COS) as carbon source showed selective growth of Lactobacillus plantarum ATCC 8014 and Lactobacillus gasseri DSM 20077. The efficient degradation of the forest biomass-derived COS by the Lactobacilli probiotic strains indicates a promising prebiotic potential. As noticed, COS from birch have positive effect for the probiotic strains, while those from spruce COS, on the other hand, did not prove to be an efficient carbohydrate substrate for the Lactobacilli strains. This can be possibly attributed to the higher lignin content of spruce and the release of products that can inhibit the growth of lactic acid bacteria after the enzymatic hydrolysis. It has been reported in the literature that the presence of phenolic compounds and furans, even in low amounts, can inhibit the growth of lactic acid bacteria [27]. The most promising probiotic strain for COS is the L. plantarum strain as it shows significantly higher growth rates and faster carbohydrate utilization than L. gasseri strain. The explanation for this is the strain's largest genome size compared to other bacterial species and therefore its ability to encode higher number of phosphotransferase system genes [28, 29]. Thus, L. plantarum strains can ferment a wider range of carbohydrates.

\section{Conclusions}

The main target of this study was to develop and optimize a novel process for the efficient production of cellobioserich hydrolysates from plant cell wall polysaccharides. These cello-oligosaccharides are produced by enzymatic hydrolysis processes using waste lignocellulosic biomass residues (birch and spruce) as substrates and are a very promising category of NDOs as they are originated by the most abundant carbon source, lignocellulose. The combination of physicochemical treatment and controlled enzymatic hydrolysis by employing a mixture of processive cellulases, together with nanofiltration for the recovery of the final product allowed the production of cellobiose from biomass. The potential of the hydrolysis products to support the in vitro growth of different Lactobacilli probiotic strains as a sole carbon source was demonstrated.

\section{Methods}

\section{Enzymes and substrates}

For the production of COS from biomass, different cellulases with processive activity were employed. 
Endo-1,4- $\beta$-D-glucanase (EG5) from Talaromyces emersonii was purchased from Megazyme (USA), while a total amount of 14 processive cellulases were purchased from NZYTech Lda. (Portugal) and are summarized in Table 10. Ten enzymes are classified in the glycoside hydrolase family 9 (GH9), two in GH48, one from GH6, and one from GH5 family. Apart from the commercially available enzymes, three in-house produced biocatalysts were used in the experiments. The enzymes included one endoglucanase of glycoside hydrolase family GH7 (TtEG7) [30], a GH7 cellobiohydrolase ( TtCBH7) [13] and an AA9 lytic polysaccharide monooxygenase (TtLPMO) [31]. The enzymes, primarily encoded by the thermophilic fungus Thermothelomyces thermophila (previously known as Myceliophthora thermophila), were heterologously produced in Pichia pastoris as previously described [13, 30, 31].

Organosolv-pretreated birch (B1: $200{ }^{\circ} \mathrm{C}$ for $15 \mathrm{~min}$, 60\% (v/v) EtOH, and B2: $200{ }^{\circ} \mathrm{C}$ for $30 \mathrm{~min}, 60 \%(\mathrm{v} / \mathrm{v})$ $\mathrm{EtOH}$ ) and spruce (S1: $200{ }^{\circ} \mathrm{C}$ for $30 \mathrm{~min}, 52 \%(\mathrm{v} / \mathrm{v})$ EtOH) were used as substrates [32, 33]. The compositional analysis of the materials was $66.3 \%(\mathrm{w} / \mathrm{w})$ cellulose, $22 \%(\mathrm{w} / \mathrm{w})$ hemicellulose, $7.8 \%(\mathrm{w} / \mathrm{w})$ lignin for B1, $67.1 \%(\mathrm{w} / \mathrm{w})$ cellulose, 21\% (w/w) hemicellulose, $7.1 \%$ (w/w) lignin for B2 and 66\% (w/w) cellulose, 6\% (w/w) hemicellulose, 14.9\% (w/w) lignin for S1 [32, 33]. Carboxymethyl cellulose (CMC), microcrystalline cellulose Avicel PH-101 and cello-oligosaccharides (DP2-6) were obtained from Sigma-Aldrich (USA). Celloheptaose (DP7) and cello-octaose (DP8) were obtained from Elicityl-Oligotech ${ }^{\circledR}$ (France). Phosphoric acid swollen cel-

\section{Screening tests on processive enzymes}

In order to select the most promising candidate to be subsequently included in the construction of an enzyme cocktail for the production of cellobiose and other prebiotic cello-oligosaccharides from biomass, initial screening of all processive enzymes against oligosaccharides and polysaccharides was performed. The enzymes were also tested as monoenzymes for their activity on pretreated natural substrates (birch and spruce as forest residues).

\section{i. Hydrolysis of polysaccharidic substrates}

The activity of all processive enzymes on PASC, Avicel and CMC was evaluated in safe lock microtubes at $1.5 \mathrm{~mL}$ reaction volume. Substrates were prepared in $50 \mathrm{mM}$ sodium acetate buffer $\mathrm{pH}$ 6.0. The initial substrate concentration was $0.5 \%(\mathrm{w} / \mathrm{v})$, and the enzyme loading was $20 \mathrm{mg} / \mathrm{g}$ substrate. All reactions were performed in $50 \mathrm{mM}$ sodium acetate buffer, under $1100 \mathrm{rpm}$ agitation and contained $0.02 \%(\mathrm{w} / \mathrm{v}) \mathrm{NaN}_{3}$. The temperature was set at 37,50 or $60{ }^{\circ} \mathrm{C}$, according to the enzyme optimal temperature of activity (Table 11). After $24 \mathrm{~h}$, samples were taken, boiled for $5 \mathrm{~min}$ for enzyme inactivation, and centrifuged and the supernatant was filtered $(0.22 \mu \mathrm{m}$ pore size). The presence of oligosaccharides was verified with high-performance anion exchange chromatography equipped with pulsed amperometric detection (HPAECPAD), as previously described [31]. Evaluation of results was based on the chromatograph peaks corresponding to sugars with DP 1-5.

The product profile as well as the total cellulose conversion into oligosaccharides was calculated with the following equation (Eq. 1):

$$
\text { Cellulose conversion }(\%)=\frac{(C 1+C 2 * 1.05+C 3 * 1.07+C 4 * 1.08+C 5 * 1.09) * 100}{\text { Csubstrate } * 1.1},
$$

lulose (PASC) was prepared from Avicel, as previously described [34]. where the concentration of glucose, oligosaccharides and initial substrate are calculated in $\mathrm{mg} / \mathrm{mL}$ of reaction volume and 1.05, 1.07, 1.08 and 1.09 are the conversion rates of cellobiose, $C 3, C 4$, and $C 5$ to glucose, respectively. The cellulose percentage for PASC, Avicel and CMC was

Table 11 Nanofiltration membranes and their characteristics

\begin{tabular}{|c|c|c|c|c|c|}
\hline Manufacturer & Type & Pore size/MWCO ${ }^{a}(\mathrm{Da})$ & Polymer & $\mathrm{pH}$ & Flux (GFD/psi) \\
\hline Dow Filmtec $^{\mathrm{TM}}$ & NF270 & $\sim 200-400$ & Polyamide-TFC & $2-11$ & 72-98/130 \\
\hline GE Osmonics $^{\mathrm{TM}}$ & $\mathrm{DL}$ & $\sim 150-300$ & Polyamide-TFC & $2-10$ & $28 / 220$ \\
\hline Synder ${ }^{\mathrm{TM}}$ & NFX & $\sim 150-300$ & Polyamide-TFC & $3-10.5$ & $20-25 / 110$ \\
\hline Synder ${ }^{\mathrm{TM}}$ & NFW & $\sim 300-500$ & Polyamide-TFC & $4-10$ & $45-50 / 110$ \\
\hline TriSep $^{\text {тм }}$ & TS40 & $\sim 200$ & Polypiperazine-amide-TFC & $2-11$ & $20 / 110$ \\
\hline
\end{tabular}

a MWCO molecular weight cut-off 
considered as $100 \%$. The degree of processivity $(P)$ was calculated by using the equation $P=(C 2-C 1) /(C 3+C 1)$, as previously described [18].

\section{ii Kinetics of oligosaccharide hydrolysis}

The mode of action of the enzymes was evaluated on cello-oligosaccharides with DP 5-8. The initial substrate concentration was $60 \mathrm{mM}$, and $4 \mu \mathrm{g}$ of each enzyme was used at a final volume of $1.5 \mathrm{~mL}$. All reactions were performed in $50 \mathrm{mM}$ sodium acetate buffer, contained $0.02 \%$ $(\mathrm{w} / \mathrm{v}) \mathrm{NaN}_{3}$. The temperature was set at 37,50 or $60{ }^{\circ} \mathrm{C}$, according to the enzyme optimal temperature of activity. For the determination of the hydrolysis kinetics, samples were taken every $20 \mathrm{~min}$ for a duration of $100 \mathrm{~min}$, boiled for $5 \mathrm{~min}$ and filtered and the released oligosaccharides were evaluated with HPAEC/PAD chromatography, as described above. The enzymatic hydrolysis of cello-oligosaccharides was considered as a first-order reaction [35], and the catalytic efficiency of the enzymes against cellooligosaccharides was estimated by the equation:

$$
k * t=\ln \frac{[\mathrm{So}]}{[\mathrm{St}]},
$$

where $k=\left(k_{\mathrm{cat}} / K_{\mathrm{m}}\right) *[E]$ and [E], [So], [St] are calculated in $\mathrm{mM}$ and represent the enzyme and the substrate concentration at the beginning of the reaction and at a specified time, respectively [30].

\section{iii Activity on lignocellulosic materials}

Organosolv-pretreated birch (B1, B2) and spruce (S1) were used as substrates to estimate the activity of the different processive enzymes on lignocellulosic feedstocks. The initial dry matter (DM) was $1.5 \%(\mathrm{w} / \mathrm{v})$, and the enzyme loading was $8 \mathrm{mg} / \mathrm{g}$ substrate. The parameters of the reaction (final volume, buffer, temperature and agitation) were similar to those described above for the hydrolysis of polysaccharidic substrates. Samples were taken at $48 \mathrm{~h}$, boiled, centrifuged and filtered, while the released oligosaccharides were evaluated with HPAECPAD chromatography, after the procedure that was previously described [31]. The degree of processivity $(P)$ was calculated by using the equation $P=(C 2-C 1) /(C 3+C 1)$, as previously described [18].

\section{Experimental design and cocktail optimization}

After selection of the most appropriate processive enzyme to be included in the subsequent design, the cello-oligosaccharide yields from organosolv-pretreated biomass using different enzyme mixtures were studied. Preliminary tests were conducted in order to set the upper and lower concentrations for each enzyme. Hydrolysis of birch and spruce (B1, B2 and S1) was performed using different combinations of two in-house produced enzymes (TtLPMO, TtCBH7) and the commercially available endoglucanase EG5. Enzymatic reactions were performed in safe lock microtubes at $1.5 \mathrm{~mL}$ reaction volume, at $50{ }^{\circ} \mathrm{C}$, under agitation of $1100 \mathrm{rpm}$, with $3 \%(\mathrm{w} / \mathrm{v})$ initial DM. The enzymes were loaded at $25 \mathrm{mg} / \mathrm{g}$ substrate. All reactions were performed in $50 \mathrm{mM}$ sodium acetate buffer $\mathrm{pH} 6.0$ and contained $0.02 \%(\mathrm{w} / \mathrm{v}) \mathrm{NaN}_{3}$. Samples were taken at $24 \mathrm{~h}$ and further processed as described above. As the main reaction products were cellobiose and glucose, sugar analysis was performed by isocratic ion-exchange chromatography, using an Aminex HPX-87H column with a micro-guard column, at $65{ }^{\circ} \mathrm{C}$ (Bio-Rad Laboratories, Hercules, CA, USA), as previously described [36]. Cellulose conversion into cellobiose was calculated by following the equation below:

$$
\text { Cellulose conversion }(\%)=\frac{C 2 * 1.05 * 100}{C_{\text {substrate }} * \% \text { cellulose } * 1.1},
$$

where the concentration of cellobiose and initial substrate is calculated in $\mathrm{mg} / \mathrm{mL}$ of reaction volume and 1.05 is the conversion rates of cellobiose to glucose. The percentage of cellulose for each substrate is described above, in Sect. "Enzymes and substrates".

For this experimental design and the cocktail optimization, four enzymes, including the most promising processive enzyme candidate that was chosen after the screening studies, EG5, TtCBH7, and TtLPMO were used. The upper and lower limits of the percentage of each enzyme were defined based on data from previous studies [13, 37] (Additional file 1: Table S6), and preliminary results conducted with EG5, TtCBH7 and TtLPMO, as described above. The different enzyme combinations are described in Additional file 1: Table S7. The in-house produced endoglucanase $M t$ EG7 was also used in all enzyme combinations, at an amount equal to $5 \%(\mathrm{w} / \mathrm{w})$ of the total cocktail. The reactions were performed with $3 \%(\mathrm{w} / \mathrm{v})$ initial dry matter and a total enzyme loading of $25 \mathrm{mg} / \mathrm{g}$ substrate in $50 \mathrm{mM}$ sodium acetate buffer $\mathrm{pH} 6.0$, as described above. Samples were taken at 24 and $48 \mathrm{~h}$. After centrifugation and boiling, the supernatants were filtered $(0.22 \mu \mathrm{m}$ pore size $)$ and the released sugars were detected by HPLC chromatography using an Aminex HPX-87H column as described above. The evaluation of the results toward the maximum cellobiose yields was performed with Design Expert 7.0.0 software using the most appropriate model that fits the experimental data $[13,37]$. $D$-optimal design was used to fit the results. The predicted enzyme combinations that could yield the optimal cellobiose production were verified experimentally. 


\section{Nanofiltration tests}

A nanofiltration system comprised of a HP4750 highpressure stirred cell and various membranes (Sterlitech, USA) was employed. The nanofiltration vessel was a magnetically stirred dead-end stainless-steel cell with a working volume of $300 \mathrm{~mL}$ and effective membrane area of $14.6 \mathrm{~cm}^{2}$. A constant pressure of $5,10,15$ or 20 bar was provided by filling nitrogen gas into the cell, while the permeate was collected in a beaker placed on an electronic scale in order to calculate the permeate flux. In the case of higher temperature conditions $\left(40,50\right.$ or $\left.60{ }^{\circ} \mathrm{C}\right)$, the nanofiltration vessel was placed in a water bath. The membranes that were used in this study, as well as their characteristics, are described in Table 11. For testing the membranes, D-glucose $(180.156 \mathrm{~g} / \mathrm{mol})$ and D-cellobiose (342.3 g/mol) were purchased from Sigma-Aldrich (USA) and were used for the model solutions.

\section{i. Water permeability measurements}

For the evaluation of water permeability properties, the membranes, stored in $1 \%(\mathrm{w} / \mathrm{v})$ sodium metabisulfite, were rinsed with $\mathrm{dH}_{2} \mathrm{O}$ and placed in the nanofiltration

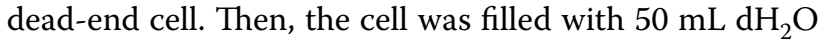
and a pressure of 10 bar was applied. Measurements of the permeate's weight were taken every $5 \mathrm{~min}$ for $20 \mathrm{~min}$ in total. The water permeability of each membrane was determined every time before and after the use of the membrane as an indication of the membrane efficiency; whenever a change was detected the membrane was discarded and replaced by a new one. The tests for the water permeability were conducted at room temperature.

The permeate's flux was calculated according to the equation (Eq. 4):

$$
J=\frac{V}{A * t}
$$

where $J$ represents the permeate flux $\left(\mathrm{L} / \mathrm{m}^{2} \mathrm{~h}\right), \mathrm{V}$ the permeate volume $(\mathrm{L}), \mathrm{A}$ the membrane area $\left(\mathrm{m}^{2}\right)$, and $\mathrm{t}$ the filtration time $(\mathrm{h})$ [38].

The water permeability of the membrane $\left(L_{\mathrm{p}}\right)$ was calculated by the equation (Eq. 5):

$$
L_{\mathrm{p}}=\frac{J_{\mathrm{w}}}{\mathrm{TMP}}
$$

where $J_{\mathrm{w}}$ represents the water flux $(\mathrm{L} / \mathrm{h})$ and TMP the transmembrane pressure $\left(\mathrm{m}^{2 *}\right.$ bar $)$.

\section{Nanofiltration of model solutions and hydrolysis products}

The model solutions that were used for the experiments were prepared with commercial glucose and cellobiose dissolved in $\mathrm{dH}_{2} \mathrm{O}$. The feed concentration that was tested was 5 and $20 \mathrm{mg} / \mathrm{mL}$. The filtration was performed at concentration ratio of cellobiose to glucose
9:1, at different pressure conditions (5, 10, 15 and 20 bar), and the experiments were carried out at room temperature. The membranes that were more suitable for the experimental purposes and led to efficient separation of cellobiose and glucose were further tested at different temperatures $\left(40,50\right.$ and $\left.60{ }^{\circ} \mathrm{C}\right)$. The feed volume was $50 \mathrm{~mL}$. During the nanofiltration process, the feed solutions were concentrated by a factor of 2 and samples of the permeate were taken every 15 min on average depending on the flow rate of the permeate. At the end of the filtration, another sample was taken from the sugar mixture that was inside of the vessel (retentate). All samples were then filtrated with $0.22-\mu \mathrm{m}$-pore-size filters and were analyzed with HPLC chromatography using an Aminex HPX-87H column, as previously described [36].

The retention of a solute $j\left(R_{j}\right)$ is obtained by the following equation:

$$
R_{j}=\left(1-\frac{C_{\mathrm{p}, j} * V_{\mathrm{p}}}{C_{\mathrm{F}, j} * V_{\mathrm{F}}}\right) * 100 \%,
$$

whereas $C_{\mathrm{p}, j}$ is the concentration of the solute $j$ in the permeate and $C_{\mathrm{F}, j}$ the concentration of the solute $j$ in the feed. $V_{\mathrm{p}}$ is the volume of the permeate, and $V_{\mathrm{F}}$ is the volume of the feed. For the calculations, the average original feed and final retentate concentration were used, as the calculation based on the time-dependent mass balance during the trials was not easy to be determined.

The cellobiose separation factor is given by the following equation, where the observed percentage retention values of cellobiose $\left(R_{\text {cell }}\right)$ and glucose $\left(R_{\mathrm{gl}}\right)$ are used. A separation factor greater than one corresponds to cellobiose enrichment in the retentate as compared to the feed solution [24]:

$$
X_{\text {cell }}=\frac{R_{\text {cell }}}{R_{\mathrm{gl}}} .
$$

Another screening of the membranes was performed using as feed a "real" lignocellulose-derived stream, more specifically a birch hydrolysate after enzymatic treatment with a commercially available cellulase mixture from Trichoderma reesei (Celluclast ${ }^{\circledR}$, Sigma-Aldrich). The aim of this test was to evaluate the performance of the membranes toward the separation of cellobiose and glucose under conditions that could mimic the real condition and, moreover, to compare the results with those in the case of the pure sugars model solution. The hydrolysis solution was produced by a $50 \mathrm{~mL}$ reaction with $3 \%$ (w/v) initial DM, $25 \mathrm{mg} / \mathrm{g}$ substrate enzyme loading and $50 \mathrm{mM}$ sodium acetate $\mathrm{pH} 5.0$ after $48 \mathrm{~h}$ of incubation. Then, it was boiled, centrifuged, filtrated with $0.22-\mu \mathrm{m}$-pore-size filter and was then used for the nanofiltration trials. The trials were carried out at the optimal 
pressure condition of $10 \mathrm{bar}$ and at room temperature for all the membranes except for the membrane NFW which showed very low performance on the previous trials with the model solution. The membranes with high performance and separation efficiency were further studied at higher temperatures $\left(40,50\right.$ and $\left.60{ }^{\circ} \mathrm{C}\right)$. Nanofiltration trials were conducted as described above, and samples from the retentate and the permeate were analyzed by HPLC chromatography.

\section{Scale-up reaction with $6 \%(\mathrm{w} / \mathrm{v}) \mathrm{DM}$ and product recovery}

After identifying the optimal enzyme combination that could maximize the cellobiose yield on birch and spruce biomass, a scale-up reaction was set up by employing the optimal enzyme ternary mixture. The initial dry matter was $6 \%(\mathrm{w} / \mathrm{v})$ and the enzyme loading was $25 \mathrm{mg} / \mathrm{g}$ substrate, all suspended in $15 \mathrm{mM}$ ammonium acetate buffer $\mathrm{pH}$ 6.0. The reaction total volume was $100 \mathrm{~mL}$, and the ratio of reaction volume to shake flask volume was $1 / 10$. The hydrolysis took place at $50{ }^{\circ} \mathrm{C}$, under continuous agitation of $170 \mathrm{rpm}$. The enzymes were loaded in two steps sequentially in order to maximize hydrolysis and prevent end-product inhibition, by maintaining the same total enzyme loading. First, an enzyme loading of $15 \mathrm{mg} / \mathrm{g}$ was added and was incubated for $48 \mathrm{~h}$. Then, after centrifugation, the hydrolysate was collected, the residual biomass was washed with the same buffer, and the washed hydrolysate was also collected. There was no boiling step at this stage, as the enzymes were collected through ultrafiltration (see below). The washed biomass was again placed in the shake flask, and the residual $10 \mathrm{mg} / \mathrm{g}$ enzyme loading was added together with the proper amount of buffer for another $48 \mathrm{~h}$. Then, the same procedure for washing the biomass was followed. All the hydrolysates (initial and after wash) were filtrated with $0.22-\mu \mathrm{m}$-pore-size filter, and then, samples were taken for HPLC analysis for identifying and quantifying the cellobiose and glucose content using an Aminex HPX-87H column, as previously described [19]. Then, all were mixed in one hydrolysate that was further processed to ultrafiltration for the removal of the enzymes and nanofiltration for the glucose removal.

For the removal of the total protein, the hydrolysate was filtrated with a LabScale Tangential Flow Filtration system (TFF) (Millipore) with exclusion membrane size $5 \mathrm{kDa}$ (Pellicon XL Ultrafiltration Module Biomax $5 \mathrm{kDa}$, Millipore). The retentate, containing the concentrated solution of cellulases, was maintained in $4{ }^{\circ} \mathrm{C}$ for further use in other hydrolysis experiments. The permeate was then collected and applied to nanofiltration system by using the NF270 membrane. The retentate was collected, freeze-dried and stored in a dry place until further use. Samples from all the different steps of the process were collected and analyzed by HPLC [36] in order to determine the sugar content and the presence of acids originating from biomass components (hemicellulose) or reaction conditions (buffer).

\section{Evaluation of prebiotic activity of $\operatorname{COS}$}

Birch- and spruce-derived cello-oligosaccharides (COS) produced after enzymatic hydrolysis were used for prebiotic tests at an initial concentration of $2 \%(\mathrm{w} / \mathrm{v})$. The hydrolysis products were tested whether they could be utilized as carbon sources and support the growth of probiotic strains. Six bacterial strains belonging to the lactobacilli and bifidobacteria species (3 strains for each species, respectively) were included in this study as they are representative species with probiotic properties. Bifidobacterium adolescentis DSM 20083, Bifidobacterium longum DSM 20219, Lactobacillus gasseri DSM 20077 and Lactobacillus reuteri DSM 20016 were purchased from DSMZ (Braunschweig, Germany). Bifidobacterium animalis subsp. lactis was a generous offer from Essum Probiotics AB, Umeå, Sweden. Lactobacillus plantarum ATCC 8014 was obtained from ATCC (VA, USA). The growth medium for the Lactobacillus strains stock cultures was MRS medium with cysteine (Medium 232 DSMZ), while in the case of Bifidobacteria strains, the Bifidobacterium medium (Medium 58 DSMZ) was used. When cellobiose and COS were tested as carbon source, both bacterial species were cultivated in in-house prepared MRS broth in the absence of glucose or any other carbohydrate. The $\mathrm{pH}$ of the medium was adjusted to 6.0.

Cultivation took place anaerobically at the optimal growth temperature of $37^{\circ} \mathrm{C}$ from stock cultures. The stock cultures were maintained at $-80{ }^{\circ} \mathrm{C}$ in the appropriate medium supplemented with $50 \%(\mathrm{v} / \mathrm{v})$ glycerol as a cryoprotectant. Cells from the culture broth of each species were subcultured $(5 \% \mathrm{v} / \mathrm{v})$ into fresh media and incubated $24 \mathrm{~h}$ anaerobically at $37^{\circ} \mathrm{C}$. Growth rate was monitored by identifying the optical density of $600 \mathrm{~nm}$ $\left(\mathrm{OD}_{600}\right)$. The $\mathrm{OD}$ of the preculture was measured, and the volume of the inoculum was then calculated in order for the starting OD of the main culture to be equal to 0.3 . To test the effectiveness of cellobiose as prebiotic candidate, the growth of all strains on pure cellobiose as carbon source was tested as a positive control. The cells from the glucose precultures were collected after centrifugation at $4000 \mathrm{rpm}$ for $10 \mathrm{~min}$ and resuspended in $50 \mathrm{~mL}$ MRS medium containing $2 \%(\mathrm{w} / \mathrm{v})$ cellobiose instead of glucose. The incubation for all the cultures was achieved in a vinyl anaerobic chamber (COY Laboratory products, USA) under strict anaerobic atmosphere using a regulated gas mixture, for a maximum of $190 \mathrm{~h}$. Growth 
rate was monitored by identifying the $\mathrm{OD}_{600}$, while sugar consumption and release of fermentation products [lactic acid and other short chain fatty acids (SCFA)] were analyzed using HPLC chromatography with Aminex HPX87H column as described above [36]. All trials were run in duplicates. Cultures with MRS media with $2 \%(\mathrm{w} / \mathrm{v})$ glucose, as well as in the absence of any carbon source, were used for comparison.

The selected strains (Lactobacilli strains) that were able to efficiently grow on cellobiose were further tested on birch- and spruce-derived COS. $2 \%(\mathrm{w} / \mathrm{v})$ cellobiose content media were prepared from the final hydrolysis products of the scale-up reactions, where the sugars were dissolved directly in MRS broth. The final product from spruce hydrolysis reaction was proved to be difficulty dissolved and required heating to $60{ }^{\circ} \mathrm{C}$. The obtained media were then sterilized by membrane filtration using $0.22-\mu \mathrm{m}$-pore-size filters. The reaction conditions were similar to those followed for pure cellobiose, while the determination of growth rate and production of metabolites were conducted as described above.

\section{Supplementary information}

Supplementary information accompanies this paper at https://doi. org/10.1186/s13068-019-1628-z.

Additional file 1: Table S1. Product profile and \% w/w cellulose conversion into soluble oligosaccharides from pure cellulosic substrates. Table S2. Product profile and \% w/w cellulose conversion into soluble oligosaccharides from lignocellulosic substrates. Table S3. Cellobiose yield for 24 and $48 \mathrm{~h}$ of hydrolysis of organosolv-pretreated spruce (S1) and birch (B1). The response factor (\% w/w cellobiose) refers to the \% W/W conversion of cellulosic biomass content into cellobiose. Table S4. Final equations in terms of actual components for spruce (S1) and birch (B1) experimental design. Table S5. Average water permeability for all the membranes. Table S6. Upper and lower limits for all variables used for the experimental design. Table S7. Enzyme combinations for the optimization tests generated with D-optimal experimental design (Design Expert ${ }^{\circledR}$ 7.0.0, Stat-Ease Inc.). Figure S1. Ternary plots displaying the predicted cellobiose concentration ( $\mathrm{mg} / \mathrm{mL}$ ) from birch hydrolysis at 24 (A) and 48 $h(B)$, as a function of three out of four enzymes. For each plot, the fourth enzyme ("Actual Component") is set at the relative proportion of the point yielding the maximum amount of cellobiose, as predicted by the statistical model. Figure S2. Ternary plots displaying the predicted cellobiose concentration $(\mathrm{mg} / \mathrm{mL})$ from spruce hydrolysis at $24(\mathrm{~A})$ and $48 \mathrm{~h}(\mathrm{~B})$, as a function of three out of four enzymes. For each plot, the fourth enzyme ("Actual Component") is set at the relative proportion of the point yielding the maximum amount of cellobiose, as predicted by the statistical model.

\section{Abbreviations}

COS: cello-oligosaccharides; EG: endoglucanase; $\mathrm{CBH}$ : cellobiohydrolase; LPMO: lytic polysaccharide monooxygenase; PASC: phosphoric-acid swollen cellulose; CMC: carboxymethyl cellulose.

\section{Acknowledgements}

Eva Grahn Håkansson from Essum Probiotics AB is greatly acknowledged for providing the $B$. animalis probiotic strain, as well as her expertise regarding the prebiotic activity tests. Sveaskog is greatly acknowledged for providing the forest materials.

\section{Authors' contributions}

AK participated in the conceptualization and design of the study, performed part of the experimental work (hydrolysis tests and evaluation of evaluation of prebiotic activity) and wrote the manuscript. LM contributed to supervision, data interpretation as well as manuscript review and editing. EK performed the experimental work (nanofiltration tests and evaluation of prebiotic activity). UR and PC participated in the study conception, project administration and funding acquisition and reviewed the manuscript. All authors read and approved the final manuscript.

\section{Funding}

Open access funding provided by Lulea University of Technology. This work was partially funded by Vinnova, Biolnnovation Program Food-grade prebiotic oligosaccharide production, merging marine, and forest resources for moving up the cellulose value-chain (ForceUpValue). Bio4Energy, a strategic research environment appointed by the Swedish government, is also acknowledged for supporting this work.

\section{Availability of data and materials}

COS from enzymatic hydrolysis of birch biomass are available upon reasonable request.

\section{Ethics approval and consent to participate}

Not applied.

\section{Consent for publication}

Not applied.

Competing interests

The authors declare that they have no competing interests.

Received: 25 September 2019 Accepted: 4 December 2019

Published online: 10 December 2019

\section{References}

1. Gibson GR, Roberfroid MB. Dietary modulation of the human colonic microbiota: introducing the concept of prebiotics. J Nutr. 1995;125:140112. https://doi.org/10.1093/jn/125.6.1401.

2. Roberfroid M. Prebiotics: the concept revisited. J Nutr. 2007;137:830S-7S. https://doi.org/10.1093/jn/137.3.830S

3. Chen YS, Srionnual S, Onda T, Yanagida F. Effects of prebiotic oligosaccharides and trehalose on growth and production of bacteriocins by lactic acid bacteria. Lett Appl Microbiol. 2007;45:190-3. https://doi. org/10.1111/j.1472-765X.2007.02167.x.

4. Manning TS, Gibson GR. Prebiotics. Best Pract Res Clin Gastroenterol. 2004;18:287-98. https://doi.org/10.1016/j.bpg.2003.10.008.

5. Mussatto SI, Mancilha IM. Non-digestible oligosaccharides: a review. Carbohydr Polym. 2007;68:587-97. https://doi.org/10.1016/j.carbp ol.2006.12.011.

6. Swennen K, Courtin CM, Delcour JA. Non-digestible oligosaccharides with prebiotic properties. Crit Rev Food Sci Nutr. 2006;46:459-71. https:// doi.org/10.1080/10408390500215746.

7. Roberfroid M, Slavin J. Nondigestible oligosaccharides. Crit Rev Food Sci Nutr. 2000;40:461-80. https://doi.org/10.1080/10408690091189239.

8. Song J, Jiao LF, Xiao K, Luan ZS, Hu CH, Shi B, et al. Cellooligosaccharide ameliorates heat stress-induced impairment of intestinal microflora, morphology and barrier integrity in broilers. Anim Feed Sci Technol. 2013;185:175-81. https://doi.org/10.1016/j.anifeedsci.2013.08.001.

9. Otsuka M, Ishida A, Nakayama Y, Saito M, Yamazaki M, Murakami H, et al. Dietary supplementation with cellooligosaccharide improves growth performance in weanling pigs. Anim Sci. 2004;75:225-9. https://doi.org/1 0.1111/j.1740-0929.2004.00180.x.

10. Satouchi M, Watanabe T, Wakabayashi S, Ohokuma K, Koshijma T, Kuwahara M. Digestibility, absorptivity and physiological effects of cellooligosaccharides in human and rat. J Jpn Soc Nutr Food Sci. 1996;49:143-8. https://doi.org/10.4327/jsnfs.49.143.

11. Uyeno Y, Kawashima K, Hasunuma T, Wakimoto W, Noda M, Nagashima S, et al. Effects of cellooligosaccharide or a combination of 
cellooligosaccharide and live Clostridium butyricum culture on performance and intestinal ecology in Holstein calvesfed milk or milk replacer. Livest Sci. 2013;153:88-93. https://doi.org/10.1016/j.livsci.2013.02.005.

12. Kontula P, von Wright A, Mattila-Sandholm T. Oat bran beta-gluco- and xylo-oligosaccharides as fermentative substrates for lactic acid bacteria. Int J Food Microbiol. 1998;45(2):163-9.

13. Karnaouri A, Topakas E, Matsakas L, Rova U, Christakopoulos P. Fine-tuned enzymatic hydrolysis of organosolv pretreated forest materials for the efficient production of cellobiose. Front Chem. 2018;6:128. https://doi. org/10.3389/fchem.2018.00128.

14. Wilson DB, Kostylev M. Cellulase processivity. Methods Mol Biol. 2012;908:93-9. https://doi.org/10.1007/978-1-61779-956-3_9.

15. Zhang KD, Li W, Wang YF, Zheng YL, Tan FC, Ma XQ, Yao LS, Bayer EA, Wang LS, Li FL. Processive degradation of crystalline cellulose by a multimodular endoglucanase via a wire-walking mode. Biomacromolecules. 2018;19(5):1686-96. https://doi.org/10.1021/acs.biomac.8b00340.

16. Hu J, Arantes V, Pribowo A, Gourlay K, Saddler J. Substrate factors that influence the synergistic interaction of AA9 and cellulases during the enzymatic hydrolysis of biomass. Energy Environ Sci. 2014;7:2308-15. https://doi.org/10.1039/C4EE00891J.

17. Villares A, Moreau C, Bennati-Granier C, Garajova S, Foucat L, Falourd X, Saake B, Berrin JG, Cathala B. Lytic polysaccharide monooxygenases disrupt the cellulose fibers structure. Sci Rep. 2017;7:40262. https://doi. org/10.1038/srep40262.

18. Vuong TV, Wilson DB. Processivity, synergism, and substrate specificity of Thermobifida fusca Cel6B. Appl Environ Microbiol. 2009;75:6655-61. https ://doi.org/10.1128/AEM.01260-09.

19. Parsiegla G, Reverbel C, Tardif C, Driguez H, Haser R. Structures of mutants of cellulase Cel $48 \mathrm{~F}$ of Clostridium cellulolyticum in complex with long hemithio-cellooligosaccharides give rise to a new view of the substrate pathway during processive action. J Mol Biol. 2008;375(2):499-510. https ://doi.org/10.1016/j.jmb.2007.10.039.

20. Li Y, Irwin DC, Wilson DB. Processivity, substrate binding, and mechanism of cellulose hydrolysis by Thermobifida fusca Cel9A. Appl Environ Microbiol. 2007;73(10):3165-72. https://doi.org/10.1128/AEM.02960-06.

21. Kurasin M, Väljamäe P. Processivity of cellobiohydrolases is limited by the substrate. J Biol Chem. 2011;286(1):169-77. https://doi.org/10.1074/jbc. m110.161059.

22. Hoshino E, Sasaki Y, Okazaki M, Nisizawa K, Kanda T. Synergistic actions of exo-type cellulases in the hydrolysis of cellulose with different crystallinities. J Biochem. 1993;114:230-5.

23. Watson BJ, Zhang H, Longmire AG, Moon YH, Hutcheson SW. Processive endoglucanases mediate degradation of cellulose by Saccharophagus degradans. J Bacteriol. 2009;191:5697-705. https://doi.org/10.1128/ JB.00481-09.

24. Morthensen ST, Luo J, Meyer AS, Jørgensen H, Pinelo M. High performance separation of xylose and glucose by enzyme assisted nanofiltration. J Membr Sci. 2015;492:107-15. https://doi.org/10.1016/j.memsc i.2015.05.025

25. Mah KH, Yussof HW, Jalanni NA, Seman MNA, Zainol N. Separation of xylose from glucose using thin film composite (TFC) nanofiltration membrane: effect of pressure, total sugar concentration and xylose/glucose ratio. J Teknol. 2014:1:93-8. https://doi.org/10.11113/jt.v70.2746.

26. Sharma RR, Agrawal R, Chellam S. Temperature effects on sieving characteristics of thin-film composite nanofiltration membranes: pore size distributions and transport parameters. J Membr Sci. 2003;223:69-87. https://doi.org/10.1016/S0376-7388(03)00310-7.

27. Boguta AM, Bringel F, Martinussen J, Jensen PR. Screening of lactic acid bacteria for their potential as microbial cell factories for bioconversion of lignocellulosic feedstocks. Microb Cell Fact. 2014;13:97. https://doi. org/10.1186/s12934-014-0097-0.

28. Cai H, Thompson R, Budinich MF, Broadbent JR, Steele JL. Genome sequence and comparative genome analysis of Lactobacillus casei: insights into their niche-associated evolution. Genome Biol Evol. 2009;1:239-57. https://doi.org/10.1093/gbe/evp019.

29. Morita H, Toh H, Oshima K, Murakami M, Taylor TD, Igimi S, Igimi S, Hattori M. Complete genome sequence of the probiotic Lactobacillus rhamnosus ATCC 53103. J Bacteriol. 2009;191(24):7630-1. https://doi.org/10.1128/ JB.01287-09.

30. Karnaouri AC, Topakas E, Christakopoulos P. Cloning, expression, and characterization of a thermostable GH7 endoglucanase from Myceliophthora thermophila capable of high-consistency enzymatic liquefaction. Appl Microbiol Biotechnol. 2014;98:231-42. https://doi.org/10.1007/ s00253-013-4895-9.

31. Karnaouri A, Muraleedharan MN, Dimarogona M, Topakas E, Rova U, Sandgren M, Christakopoulos P. Recombinant expression of thermostable processive MtEG5 endoglucanase and its synergism with MtLPMO from Myceliophthora thermophila during the hydrolysis of lignocellulosic substrates. Biotechnol Biofuels. 2017;10:126. https://doi.org/10.1186/s1306 8-017-0813-1.

32. Matsakas L, Nitsos C, Raghavendran V, Yakimenko O, Persson G, Olsson E, Rova U, Olsson L, Christakopoulos P. A novel hybrid organosolv: steam explosion method for the efficient fractionation and pretreatment of birch biomass. Biotechnol Biofuels. 2018;11:1-14. https://doi.org/10.1186/ s13068-018-1163-3.

33. Matsakas L, Raghavendran V, Yakimenko O, Persson G, Olsson E, Rova U, Olsson L, Christakopoulos P. Lignin-first biomass fractionation using a hybrid organosolv—steam explosion pretreatment technology improves the saccharification and fermentability of spruce biomass. Bioresour Technol. 2019:273:521-8. https://doi.org/10.1016/j.biortech.2018.11.055.

34. Wood TM. Preparation of crystalline, amorphous, and dyed cellulase substrates. Method Enzymol. 1988;160:19-25. https://doi.org/10.1016/00766879(88)60103-033.

35. Matsui I, Ishikawa K, Matsui E, Miyairi S, Fukui S, Honda K. Subsite structure of Saccharomycopsis alpha- amylase secreted from Saccharomyces cerevisiae. J Biochem. 1991;109:566-9.

36. Karnaouri A, Rova U, Christakopoulos P. Effect of different pretreatment methods on birch outer bark: new biorefinery routes. Molecules. 2016;21(4):427. https://doi.org/10.3390/molecules21040427.

37. Karnaouri A, Matsakas L, Topakas E, Rova U, Christakopoulos P. Development of thermophilic tailor-made enzyme mixtures for the bioconversion of agricultural and forest residues. Front Microbiol. 2016;16(7):177. https:// doi.org/10.3389/fmicb.2016.00177.

38. Dalwani M, Benes NE, Bargeman G, Stamatialis D, Wessling M. A method for characterizing membranes during nanofiltration at extreme $\mathrm{pH}$. J Membr Sci. 2010;363:188-94. https://doi.org/10.1016/j.memsc i.2010.07.025

\section{Publisher's Note}

Springer Nature remains neutral with regard to jurisdictional claims in published maps and institutional affiliations.

\footnotetext{
Ready to submit your research? Choose BMC and benefit from:

- fast, convenient online submission

- thorough peer review by experienced researchers in your field

- rapid publication on acceptance

- support for research data, including large and complex data types

- gold Open Access which fosters wider collaboration and increased citations

- maximum visibility for your research: over $100 \mathrm{M}$ website views per year
}

At BMC, research is always in progress.

Learn more biomedcentral.com/submissions 